\title{
Effect of pasture versus indoor feeding systems on quality characteristics, nutritional composition, and sensory and volatile properties of full-fat Cheddar cheese
}

\author{
Tom F. O’Callaghan, ${ }^{\dagger} \ddagger$ David T. Mannion, ${ }^{*}$ Deirdre Hennessy, $§$ Stephen McAuliffe, §\# Maurice G. O’Sullivan,॥ \\ Natasha Leeuwendaal, ${ }^{\star} \ddagger$ Tom P. Beresford, ${ }^{*}$ Pat Dillon,§ Kieran N. Kilcawley, ${ }^{*}$ Jeremiah J. Sheehan, ${ }^{*}$ \\ R. Paul Ross, ${ }^{*}+\pi$ and Catherine Stanton ${ }^{*}{ }^{1}$ \\ ${ }^{*}$ Teagasc Food Research Centre, Moorepark, Fermoy, Cork, Ireland P61 C996 \\ †APC Microbiome Institute, and \\ ‡Department of Microbiology, University College Cork, Cork, Ireland T12 YN60 \\ §Teagasc, Animal \& Grassland Research and Innovation Centre, Moorepark, Fermoy, Cork, Ireland P61 C996 \\ \#School of Biological Sciences, Queen's University, Belfast, BT7 1NN, United Kingdom \\ \|School of Food and Nutritional Sciences, and \\ TCollege of Science Engineering and Food Science, University College Cork, Cork, Ireland T12 YN60
}

\section{ABSTRACT}

The purpose of this study was to investigate the effects of pasture-based versus indoor total mixed ration (TMR) feeding systems on the chemical composition, quality characteristics, and sensory properties of fullfat Cheddar cheeses. Fifty-four multiparous and primiparous Friesian cows were divided into 3 groups ( $\mathrm{n}=$ 18) for an entire lactation. Group 1 was housed indoors and fed a TMR diet of grass silage, maize silage, and concentrates; group 2 was maintained outdoors on perennial ryegrass only pasture (GRS); and group 3 was maintained outdoors on perennial ryegrass/white clover pasture (CLV). Full-fat Cheddar cheeses were manufactured in triplicate at pilot scale from each feeding system in September 2015 and were examined over a 270-d ripening period at $8^{\circ} \mathrm{C}$. Pasture-derived feeding systems were shown to produce Cheddar cheeses yellower in color than that of TMR, which was positively correlated with increased cheese $\beta$-carotene content. Feeding system had a significant effect on the fatty acid composition of the cheeses. The nutritional composition of Cheddar cheese was improved through pasture-based feeding systems, with significantly lower thrombogenicity index scores and a greater than 2 -fold increase in the concentration of vaccenic acid and the bioactive conjugated linoleic acid C18:2 cis-9,trans-11, whereas TMR-derived cheeses had significantly higher palmitic acid content. Fatty acid profiling of cheeses coupled with multivariate analysis showed clear separation of Cheddar cheeses derived from pasture-based

Received December 22, 2016.

Accepted April 7, 2017.

${ }^{1}$ Corresponding author: Catherine.stanton@teagasc.ie diets (GRS or CLV) from that of a TMR system. Such alterations in the fatty acid profile resulted in pasturederived cheeses having reduced hardness scores at room temperature. Feeding system and ripening time had a significant effect on the volatile profile of the Cheddar cheeses. Pasture-derived Cheddar cheeses had significantly higher concentrations of the hydrocarbon toluene, whereas TMR-derived cheese had significantly higher concentration of 2,3-butanediol. Ripening period resulted in significant alterations to cheese volatile profiles, with increases in acid-, alcohol-, aldehyde-, ester-, and terpene-based volatile compounds. This study has demonstrated the benefits of pasture-derived feeding systems for production of Cheddar cheeses with enhanced nutritional and rheological quality compared with a TMR feeding system.

Key words: pasture, total mixed ration, cow, Cheddar cheese, fatty acid

\section{INTRODUCTION}

Cheese has been targeted as a vital added-value end product for the increased milk pool now available in Ireland following the abolition of the European Union's milk quotas in 2015 (Sheehan, 2013). Many variables can affect the quality, composition, and consumer acceptability of cheeses, including the manufacturing process, initial composition, and the quality of raw milks used (Coulon et al., 2004). Cow feeding systems have long been identified as a major factor affecting the composition and quality of milk (Palmquist et al., 1993) and dairy products such as cheese (Coakley et al., 2007; Hurtaud et al., 2009). The feeding system used by farmers is principally dictated by the cow's nutritional requirements, climatic conditions, and land availability. 
Ireland's agricultural system is based on the use of pasture as a low-cost primary feed source, where cows are calved in the spring and maintained outdoors for the majority of their lactation (O'Brien et al., 1999; Shalloo et al., 2004; O'Donovan et al., 2011), unlike farming systems where cows are maintained indoors year-round on a TMR diet of forage and concentrates as practiced in the United States, parts of Europe, and parts of the Southern Hemisphere (van Arendonk and Liinamo, 2003; Barberg et al., 2007). Milk and dairy products are highly nutritious food items and a significant source of dietary proteins and fats. Conjugated linoleic acid is a fatty acid (FA) bioactive isomer unique to rumen animal-derived milks and meats, widely studied because of its many health-beneficial attributes and interesting biological functions. Yang et al. (2015) reviewed the array of benefits associated with CLA, including positive effects on immune function and protective effects against cancer, obesity, diabetes, and atherosclerosis in animal and human cell line studies. Milk is also a source of n-3 and n- 6 fatty acids (omega FA), and the ideal ratio of $\mathrm{n}-3$ to $\mathrm{n}-6$ fatty acids in the diet has been reported to be from 1:1 to 1:4. However, changes in the Western diet in recent years, with increased consumption of fat and vegetable oils rich in n-6 FA, have resulted in this ratio now being between 1:10 and 1:20 (Molendi-Coste et al., 2011). There is a consumer perception that dairy products from cows maintained outdoors consuming fresh grass are "more natural" than those from cows in TMR farming systems (Verkerk, 2003). This perception has become a major marketing scheme for countries such as Ireland and New Zealand, which practice fresh grass feeding, for promotion of dairy products. The inclusion of pasture in the diets of lactating dairy cows has been shown to improve the nutritional composition of milks, particularly in terms of C18:2 CLA cis-9,trans-11 (c9t11) and n-3 FA. Couvreur et al. (2006) demonstrated a linear relationship between the proportion of fresh grass in the diet and CLA content of milks. Coakley et al. (2007) demonstrated that supplementation of cows on pasture with UFA resulted in significantly higher CLA than that of a TMR diet. A recent review of the topic has highlighted that the consumed amount of CLA required to result in observable health benefits ranges between 0.8 and 3.0 $\mathrm{g} / \mathrm{d}$; however, the estimated average consumption in Europe, the United States, and Canada is just $0.21 \mathrm{~g} / \mathrm{d}$ (Siurana and Calsamiglia, 2016). Although consumption of milk with an improved nutritional composition can be very beneficial to an individual's overall diet, the amounts required to achieve recommended levels of these bioactive nutrients in certain cases may not be feasible. Cheese, however, is a highly consumed food item, and as such, increased intake of beneficial nutrients per meal is possible. Therefore, cheeses with improved nutritional composition offer an excellent opportunity to attain such desired levels of nutrients.

Typically, in Ireland, Cheddar cheese is ripened for 6 to 9 mo before sale. During the production and ripening process, several microbial and biochemical processes such as glycolysis, lipolysis, and proteolysis occur, contributing to the characteristics and acceptability of the final cheese product. Cheese flavor is highly dependent on these ripening-related reactions and on the compounds produced from the hydrolysis and metabolism of cheese macronutrients (Kilcawley, 2017), which in turn are influenced by the source milk composition and quality. Although research has investigated the effects of different cow feeding systems on the quality and composition of milk and dairy products, only a few studies are available that compare Ireland's somewhat unique pasture-only systems, with more conventional TMR feeding systems, on the quality and characteristics of Cheddar cheeses.

The objective of this study was to investigate the effects of 3 feeding systems: a TMR diet indoors, perennial ryegrass (Lolium perenne L.) outdoors (GRS), and perennial ryegrass/white clover (Trifolium repens L.) outdoors (CLV) on the characteristics, nutritional composition, and sensory characteristics, and volatile properties of Cheddar cheeses throughout a 9-mo ripening period.

\section{MATERIALS AND METHODS}

\section{Reagents}

Hexane, heptane, formic acid, 25\% sodium methoxide, valeric acid (C5:0), undecylic acid (C11:0), and margaric acid (C17:0) were purchased from Sigma Aldrich (Dublin, Ireland). Diethyl ether was purchased from Fisher Scientific (Dublin, Ireland). Certified free fatty acid (FFA) standard mix containing C4:0 to C22:0 free acids (GLC Reference standard 74 "Free acid"), trinonadecanoin acid (C19:0; cat. no. T-165) and a standard mix of CLA C18:2 cis-9,trans-11 and C18:2 trans-10, cis-12 (cat. no. UC-59M) were purchased from $\mathrm{Nu}-$ Chek Prep Inc. (Elysian, MN). Fatty acid methyl ester triglyceride standard mix containing $\mathrm{C} 4: 0$ to C24:0 methyl esters (cat. no. 18919-1AMP) was purchased from Sigma Aldrich). Aminopropyl cartridges (500 mg; cat no. 12102041) were obtained from Agilent Technologies (Little Island, Cork, Ireland).

\section{Experimental Design}

The experimental design for this study was the same as that previously described in studies that investigated 
butters (O'Callaghan et al., 2016a) and raw milks (O'Callaghan et al., 2016b) from these feeding systems. Fifty-four spring-calving Friesian cows were allocated to 3 groups $(\mathrm{n}=18)$ at the Teagasc Animal and Grassland Research and Innovation Centre (Moorepark, Fermoy, Co. Cork, Ireland). Groups were randomized based on milk yield, milk solids yield, calving date (mean calving date: February 19, 2015), and lactation number. Group 1 was housed indoors and fed a TMR diet; group 2 was maintained outdoors on perennial ryegrass-only pasture (GRS); and group 3 was maintained outdoors on a perennial ryegrass/white clover pasture (CLV). For further information on the chemical and nutritional values of each of the diets, see O'Callaghan et al. (2016b). Milking took place at 0730 and $1530 \mathrm{~h}$ daily. To obtain a representative sample of milk, the cows in each of the 3 feeding systems were milked separately into designated 5,000-L refrigerated tanks. The evening milk was stored at $4^{\circ} \mathrm{C}$ overnight, to which the morning milk was then added. Tanks were maintained at $4^{\circ} \mathrm{C}$ and agitated before sample collection. Milk was collected from each of the groups in the trial for cheese manufacture on 3 separate occasions over a 5 -wk period in September and early October 2015. Triplicate batches of Cheddar cheeses were produced from each feeding system, when cows were $196 \pm 10 \mathrm{~d}$ in lactation on their respective diets, and each of the Cheddar cheeses within each batch were manufactured on the same day.

\section{Sample Collection and Cheddar Cheese Manufacture}

Cheddar cheese-making trials were performed in triplicate at pilot scale (Moorepark Technology Ltd., Teagasc Moorepark, Fermoy, Co. Cork, Ireland) with milk from each of the 3 herds in this study only. Cheesemaking trials were performed on September 3, September 25, and October 2, 2015. Approximately 550 to 600 $\mathrm{L}$ of morning and evening milk was collected from each of the herds over a 3 -d period as described above. The milks from each herd were standardized to a protein:fat ratio of 0.95 . Milks were pasteurized at $72^{\circ} \mathrm{C}$ for $15 \mathrm{~s}$, cooled to $31^{\circ} \mathrm{C}$, and pumped into $500-\mathrm{L}$ stainless steeljacketed vats with automated variable-speed cutting and stirring equipment (APV Schweiz AG, Worb, Switzerland). A starter inoculum composed of Lactococcus lactis ssp. lactis, Lactococcus lactis ssp. cremoris, and Streptococcus thermophilus (A2055; Chr. Hansen Ireland Ltd., Co. Cork, Ireland), with an adjunct culture Lactobacillus helveticus (LHBo2; Chr. Hansen Ireland Ltd.) was used, and the cultures were added as frozen pellets directly to the cheese-making vats. After a 50min ripening interval, Chymosin (Chymax Plus, Chr. Hansen Ltd.) at a rate of $0.15 \mathrm{~mL} / 100 \mathrm{~kg}$ of milk, was diluted in 1:5 with deionized water and added to the cheesemilk. Cheeses were then manufactured according to Fenelon et al. (2000a). Cheddar cheeses were vacuum packed and stored for ripening at $8^{\circ} \mathrm{C}$. Cheddar cheese blocks $(24 \mathrm{~kg})$ from each batch for this study were ripened over a 9-mo (270-d) period. During this time, they were analyzed for chemical composition, textural properties, FA composition, proteolysis, sensory properties, and analyses of volatile compounds; $\mathrm{pH}$, color, and texture analyses were carried out on fresh samples. For the remaining analyses, samples were wrapped in aluminum foil, vacuum packed, and stored at $-80^{\circ} \mathrm{C}$. All other analyses were carried out together at the end of the ripening period.

\section{Cheese Composition}

Grated cheese samples were analyzed in duplicate for salt content by a potentiometric method (IDF, 1981), fat content of cheese was analyzed using the RöseGottlieb method (IDF, 1996) and moisture content by oven-drying at $102^{\circ} \mathrm{C}$ for $5 \mathrm{~h}$ (IDF, 1982). The $\mathrm{pH}$ of cheese was assessed after 90, 180, and $270 \mathrm{~d}$ of ripening by blending $12 \mathrm{~mL}$ of $\mathrm{H}_{2} \mathrm{O}$ with $20 \mathrm{~g}$ of grated cheese and measuring using a standard $\mathrm{pH}$ meter (Mettler Toledo MP220; Mason Technology Ltd., Dublin, Ireland) according to the method of the British Standards Institution (1976). Calcium content analysis was performed by inductively coupled plasma optical emission spectrometry following microwave-assisted acid digestion. Trans- $\beta$-carotene was saponified using ethanolic potassium hydroxide solution for $16 \mathrm{~h}$ at room temperature and extracted once with ethanol:hexane (4:3 vol/vol) and 2 times with hexane. Trans- $\beta$-carotene analysis was performed by reverse-phase (RP)-HPLC with an UV diode array detector (UV/DAD) at $452 \mathrm{~nm}$. The calibration standards used were pure compounds (purity $>98 \%$ ) from Sigma Aldrich. The purity of the standard for each calibration was determined by a series of spectrophotometric measurements (UV at 340, 455 , and $483 \mathrm{~nm}$ ). Both methods were performed by Eurofins Food Testing (Dublin, Ireland). All chemical analysis was performed after $90 \mathrm{~d}$ of ripening.

\section{Proteolysis}

Nitrogen Soluble at $\boldsymbol{p H}$ 4.6. Primary proteolysis depicted by concentration of nitrogen soluble at $\mathrm{pH} 4.6$ was determined in duplicate by the method described by Fenelon et al. (2000b) using the macro-Kjeldahl method (International Dairy Federation, 1993) and was expressed as a percentage of total nitrogen $(\mathbf{\% p H} \mathbf{p} . \mathbf{6 -}$ $\mathrm{SN} / \mathrm{TN})$.

Free $\boldsymbol{A} \boldsymbol{A}$. Individual free AA (FAA) were determined on the $\mathrm{pH} 4.6$-soluble $\mathrm{N}$ extracts as described 
by Fenelon et al. (2000a) using a Jeol JLC-500V AA analyzer fitted with a Jeol $\mathrm{Na}^{+}$high-performance cation exchange column (Jeol Ltd., Tokyo, Japan). The chromatographic analyses were conducted at $\mathrm{pH} 2.2$ on samples after ripening for 90, 180, and $270 \mathrm{~d}$.

\section{Cheese Fatty Acid Analysis}

Lipid extraction, FFA solid-phase extraction, and triglyceride analysis was carried out as described by O'Callaghan et al. (2016a), except that before solvent extraction, $\sim 5 \mathrm{~g}$ of Cheddar cheese was ground with 10 $\mathrm{g}$ of anhydrous sodium sulfate in a pestle and mortar, and $0.3 \mathrm{~mL}$ of $2.5 \mathrm{M} \mathrm{H}_{2} \mathrm{SO}_{4}$ and $1 \mathrm{~mL}$ of internal free acid standard (ISTD; C5:0, C11:0, C17:0 at 1,000 ppm in heptane) was added to the sample mixture.

Methyl Ester Derivatization of FFA Extract. The FFA extract $(300 \mu \mathrm{L})$ was transferred into a capped (polytetrafluoroethylene/white silicone cap; Agilent Technologies) 2-mL amber GC vial (Agilent Technologies) and tetramethylammonium hydroxide (TMAH) reagent $(60 \mu \mathrm{L})$ was added to the sealed vial containing the FFA extract. This was vortexed at 3,000 rpm for 1 min using a pulsed bidirectional spin of $5 \mathrm{~s}$ with a 1 -s pause. Deionized water $(300 \mu \mathrm{L})$ was added to the mixture and this was further vortexed for $1 \mathrm{~min}$ at $1,000 \mathrm{rpm}$. An aliquot of $100 \mu \mathrm{L}$ of this aqueous layer was transferred to a sealed GC vial containing a $250-\mu \mathrm{L}$ glass insert (cat. no. 5181-8872, Agilent Technologies) and $2.0 \mu \mathrm{L}$ was injected onto the GC for analysis. The glass insert was used to allow a small volume to be sampled correctly using a GC autosampler.

Instrument Conditions for Analysis of FFA. The injector was held at $300^{\circ} \mathrm{C}$ for the entire run and was operated in split/splitless mode using a split of 1:20. The inlet liner used was a wool packed liner (cat. no. 8004-0118, Agilent Technologies). The column oven temperature was held at $40^{\circ} \mathrm{C}$ for $2 \mathrm{~min}$ and raised to $240^{\circ} \mathrm{C}$ at $7.5^{\circ} \mathrm{C} / \mathrm{min}$ and held for $7 \mathrm{~min}$. The total runtime was $35.7 \mathrm{~min}$. The flame-ionization detector was operated at $300^{\circ} \mathrm{C}$. The carrier gas was helium, which was held at a constant flow of $1.2 \mathrm{~mL} / \mathrm{min}$.

Health indices of cheese triglyceride content, atherogenicity index (AI) and thrombogenicity index (TI), were calculated as described by Ulbricht and Southgate (1991):

$$
\mathrm{AI}=\frac{\mathrm{C} 12: 0+(4 \times \mathrm{C} 14: 0)+\mathrm{C} 16: 0}{\mathrm{n}-6 \text { PUFA }+\mathrm{n}-3 \text { PUFA }+ \text { MUFA }} ;
$$

$\mathrm{TI}=$

$\mathrm{C} 14: 0+\mathrm{C} 16: 0+\mathrm{C} 18: 0$

$\overline{(0.5 \times \text { MUFA })+(0.5 \times n-6 \text { PUFA })+(3 \times n-3 \text { PUFA })+\left(\frac{n-3 \text { PUFA }}{n-6 \text { PUFA }}\right)}$

\section{Texture Profile Analysis}

Six cube-shaped samples $\left(2.5 \mathrm{~cm}^{3}\right)$ were cut from each cheese in each batch, wrapped tightly in aluminum foil, and stored at refrigeration temperature $\left(4^{\circ} \mathrm{C}\right)$ overnight. Texture analysis was performed on cheese cubes at refrigeration temperature after 90 and $270 \mathrm{~d}$ of ripening, and texture analysis was carried out on cheese cubes at room temperature after $270 \mathrm{~d}$ of ripening. For refrigerated analysis, each cube was taken from the refrigerator and immediately compressed, in 2 successive bites, to $60 \%$ of its original height at a rate of $60 \mathrm{~mm} /$ min on a TAHDi texture profile analyzer (TPA; Stable Micro Systems, Surrey, UK) at room temperature. For analysis of cheese cubes at room temperature, cubes were left wrapped in tin foil in a temperature-controlled room at $20^{\circ} \mathrm{C}$ for $3 \mathrm{~h}$ to acclimate and were then analyzed as outlined above. The following parameters were defined from the resultant force-time curve: hardness, chewiness, springiness, and cohesiveness, as described and defined by Gunasekaran and Ak (2002).

\section{Color}

Color measurements were taken from the surface of Cheddar cheese blocks after 90, 180, and $270 \mathrm{~d}$ of ripening. Five replications of $\mathrm{L}^{*}$ (lightness-darkness), $\mathrm{a}^{*}$ (green-red) and $\mathrm{b}^{*}$ (blue-yellow) values were taken at random locations across the surface of the cheeses using a Minolta Chroma-Meter CR-400 (Mason Technology Ltd.).

\section{Volatile Analysis of Cheeses}

Volatile analysis of cheeses was performed after 90, 180 , and $270 \mathrm{~d}$ of ripening using methods similar to those described by O'Callaghan et al. (2016a); $4 \mathrm{~g}$ of grated cheese sample from each trial was analyzed in triplicate.

\section{Sensory Analysis}

Sensory Affective Evaluation. Twenty-four consumers were recruited from University College Cork, Ireland, and sensory acceptance testing was conducted using these untrained assessors (Stone and Sidel, 2004; Stone et al., 2012a). The age range of assessors was 21 to $48 \mathrm{yr}$. Selection criteria for consumers were availability and motivation to participate on all days of the experiment and that they were Cheddar cheese consumers. Assessors used the sensory hedonic descriptors in Supplementary Table S1 (https://doi.org/10.3168/ jds.2016-12508) for Cheddar cheeses from each of the 3 feeding systems, presented in triplicate (from each 
manufactured batch) at 2 time points, 180 and $270 \mathrm{~d}$ of ripening. Sensory analysis was carried out in panel booths conforming to international standards (ISO, 1988). All samples were blast frozen to $-20^{\circ} \mathrm{C}$ and then stored at $-20^{\circ} \mathrm{C}$ until required. Samples, coded with a randomly selected 3 -digit code, were then held overnight $\left(4^{\circ} \mathrm{C}\right)$, before monadic presentation to the naïve assessor panel at ambient temperature $\left(21^{\circ} \mathrm{C}\right)$. Each assessor was provided with deionized water and instructed to cleanse their palates between tastings. Additionally, each assessor was asked to indicate their degree of liking on a $10-\mathrm{cm}$ line scale ranging from 0 (dislike extremely) at the left to 10 (like extremely). The order of the presentation of all test samples was randomized to prevent first-order and carryover effects, and all samples were presented in triplicate.

Ranking Descriptive Analysis. Twenty-five panelists were recruited from University College Cork, Ireland. Age range of assessors was 22 to 48 yr. Selection criteria for panelists were availability and motivation to participate on all days of the experiment and that they were Cheddar cheese consumers. Panelists used the sensory intensity descriptors described in Supplementary Table S1 (https://doi.org/10.3168/ jds.2016-12508). Ranking descriptive analysis (RDA; Dairou and Sieffermann, 2002; Richter et al., 2010) was carried out in panel booths conforming to international standards (ISO, 1988) on the 3 Cheddar cheese samples to be tested over the 2 time points of ripening (180 and 270d). All samples were stored at $-20^{\circ} \mathrm{C}$ until required. Samples were then held at refrigeration temperatures overnight $\left(4^{\circ} \mathrm{C}\right)$, before being presented to the consumer panel at ambient temperatures $\left(21^{\circ} \mathrm{C}\right)$ and coded with a randomly selected 3 -digit code. The cheeses were immediately served to panelists simultaneously for separate time points. All analysis was conducted in triplicate significantly increasing the validity of results (Stone et al., 2012a,b).Therefore, each sample was tested 75 times $(25 \times 3)$ for each hedonic attribute and the significant trends of the correlation of treatments and sensory variables are discussed. Each assessor was provided with deionized water and instructed to cleanse their palates between tastings. Additionally, each assessor was presented with triplicate samples (over separate sessions) and asked to assess the intensity of the attributes, according to a $10-\mathrm{cm}$ line scale ranging from 0 (none) at the left to 10 (extreme) at the right and rating subsequently scored from the left. The order of the presentation of all test samples was randomized to prevent first-order and carryover effects. The panelists used in the RDA were trained in partial accordance with Richter et al. (2010). Again, one training session was conducted to demonstrate the score sheet used in the RDA. In Richter et al. (2010), due to the number of attributes, the panel opted to evaluate the samples in 2 phases sequentially: one for analysis of appearance and aroma attributes and another for texture and flavor attributes. However, in the current study, the assessors opted to evaluate all attributes over a single session because they had previously participated in sensory descriptive analysis of Cheddar cheese and were familiar with the lexicon presented. Ranking descriptive analysis has been successfully demonstrated for several other products, including chocolate pudding (Richter et al., 2010) white pudding (Fellendorf et al., 2015), black pudding (Fellendorf et al., 2016), butter (O'Callaghan et al., 2016a), and mozzarella cheese (Henneberry et al., 2016). Although not a replacement for quantitative descriptive analysis (QDA), the RDA approach uses a much-reduced lexicon (19 attributes) compared with QDA, and identified the main sensory trends between treatments and sensory variables for the sample set analyzed.

\section{Statistical Analysis}

Statistical analysis was performed using SPSS v18.0 (IBM Statistics Inc., Armonk, NY). Data sets were analyzed for normality using the Shapiro-Wilk test and for homogeneity of variance using the Levene test. Analyses that were carried out at only one time point and were normally distributed were analyzed using one-way ANOVA with post hoc Tukey test. For data sets from analyses that were carried out at several time points throughout the study, a between- and withinsubjects repeated-measures ANOVA with post hoc Tukey test was used to compare Cheddar cheeses from herds on different feeding systems (TMR, GRS and CLV) (treatment) throughout the 270-d ripening period (time). Pearson correlation analysis between attributes was carried out in GraphPad Prism v7.01 for Windows (GraphPad Software, La Jolla, CA). Multivariate data analysis (partial least squares regression and principal component analysis) was applied to investigate relationships between triglyceride FA, sensory analysis, and volatiles analysis data and the experimental treatments (different feeding systems) using The Unscrambler X multivariate analysis program, v10.3 (CAMO ASA, Trondheim, Norway); $P$-values $<0.05$ were considered significant.

\section{RESULTS AND DISCUSSION}

\section{Cheese Composition}

Results for chemical analyses of cheeses are shown in Table 1. The chemical composition of the cheeses (fat, protein, moisture) was similar to that previously 
described for a full-fat Cheddar cheese (Fenelon and Guinee, 2000; Guinee et al., 2000). Feeding system had a significant effect on the $\beta$-carotene content of the cheeses: GRS-derived Cheddar cheeses having the highest $\beta$-carotene content, which was significantly higher than that of CLV $(P=0.02)$. Both GRS- and CLV-derived cheeses had a $\beta$-carotene concentration more than twice that of TMR cheese $(P<0.001)$. Feeding system did not have a significant effect on the $\mathrm{pH}$ of cheeses during ripening. Cheese $\mathrm{pH}$ significantly increased $(P$ $<0.001$ ) throughout ripening as expected, from (mean \pm SD) $5.27 \pm 0.04$ at $90 \mathrm{~d}$ to $5.43 \pm 0.06$ after $270 \mathrm{~d}$ of ripening. Previous studies investigating the effects of feeding systems have reported no differences in the chemical compositions of cheeses (Coakley et al., 2007). The increased $\beta$-carotene content of pasture-derived cheeses was in agreement with $\beta$-carotene levels of butters produced from theses diets (O'Callaghan et al., 2016a). The level of $\beta$-carotene in dairy products is highly dependent on the dietary supply of the pigment, which is most abundant in fresh pastures and substantially depleted in conserved forages, and is very low in maize or grain-based diets, resulting in whiter dairy products (Martin et al., 2005). As a result, the $\beta$-carotene content of dairy products has been suggested as a potential biomarker for milk products derived from pasture-based feeding systems (Noziere et al., 2006).

\section{Color}

Feeding system and ripening period had a significant effect on the color of Cheddar cheeses, as shown in Figure 1. The TMR-derived cheeses had significantly higher $(P=0.002) L^{*}$ scores than GRS and CLV cheeses, at (mean $\pm \mathrm{SD}) 80.19 \pm 1.51,77.97 \pm 1.63$, and $77.89 \pm 1.53$, respectively. We detected no significant difference between GRS and CLV L* values. The $\mathrm{L}^{*}$ values of each of the cheeses increased significantly throughout ripening $(P=0.001)$. The GRS- and CLVderived cheeses had the lowest $\mathrm{a}^{*}$ values on average throughout ripening, at $-4.31 \pm 0.59$ and $-4.25 \pm 0.51$, respectively, which were significantly lower than TMR at $-3.99 \pm 0.52(P=0.12$ and $P=0.03$, respectively $)$. The $\mathrm{a}^{*}$ values of the cheeses increased significantly throughout ripening $(P=0.01)$. Feeding system had a significant effect on the $b^{*}$ value of cheeses: GRS and CLV cheeses had significantly higher $\mathrm{b}^{*}$ values than TMR cheeses $(P<0.001)$, at $35.42 \pm 1.78,33.07 \pm$ 1.45 , and $25.23 \pm 1.04$, respectively. The $b^{*}$ values of cheeses decreased significantly throughout ripening $(P$ $<0.001)$. The increases in $\mathrm{L}^{*}$ and $\mathrm{a}^{*}$ and the decrease of $b^{*}$ values throughout ripening indicated that each of the cheeses became paler as ripening progressed. Juric et al. (2003) also reported an increase in a* value and decrease in $b^{*}$ values of semi-hard cheeses stored in modified-atmosphere packaging during ripening, which was attributed to light-induced degradation of carotenoids and riboflavin. Overall, these results suggest that the TMR-derived cheeses were paler than the pasturederived cheeses, and the GRS and CLV cheeses were yellower than the TMR-derived product. The color of dairy products is highly dependent on their carotenoid content (Noziere et al., 2006). Indeed, the increased b* values of the cheeses were highly correlated with their $\beta$-carotene content $(P<0.001$, Pearson $\mathrm{r}=0.948)$, whereas the $L^{*}$ values of the cheeses were negatively correlated with the $\beta$-carotene content $(P=0.004 ; \mathrm{r}$ -0.841 ). Coppa et al. (2011) reported similar alterations to the $\mathrm{b}^{*}$ value of Cantal cheeses between cows fed a hay and concentrate-based diet versus pasturebased diet.

\section{Proteolysis}

$\% p H$ 4.6-SN/TN. Overall, feeding system did not affect the primary proteolysis of cheeses during ripen-

Table 1. Mean composition (\% wt/wt unless otherwise noted; mean \pm SD) of cheeses derived from different feeding systems: TMR, perennial ryegrass (GRS), and perennial ryegrass and white clover (CLV) feeding systems

\begin{tabular}{lcccc}
\hline & & & & Treatment \\
Item $^{1}$ & TMR & GRS & CLV & 0.98 \\
\hline Protein & $26.70 \pm 0.10$ & $26.65 \pm 0.39$ & $26.64 \pm 0.37$ & 0.03 \\
Fat & $30.95 \pm 0.20$ & $30.54 \pm 0.25$ & $31.28 \pm 0.16$ & 0.78 \\
Moisture & $35.81 \pm 0.39$ & $36.21 \pm 0.60$ & $35.93 \pm 0.70$ & 0.24 \\
FDM & $48.21 \pm 0.40$ & $47.88 \pm 0.07$ & $48.84 \pm 0.78$ & 0.87 \\
MNFS & $51.85 \pm 0.57$ & $52.13 \pm 0.67$ & $52.29 \pm 1.13$ & 0.56 \\
Salt & $1.87 \pm 0.07$ & $1.83 \pm 0.06$ & $1.80 \pm 0.07$ & 0.61 \\
S/M & $5.23 \pm 0.25$ & $5.05 \pm 0.24$ & $5.00 \pm 0.18$ & 0.33 \\
Ash & $3.95 \pm 0.18$ & $4.01 \pm 0.08$ & $3.82 \pm 0.05$ & 0.46 \\
Calcium & $0.84 \pm 0.01$ & $0.82 \pm 0.02$ & $0.81 \pm 0.02$ & $<0.001$ \\
3-Carotene $(\mathrm{mg} / \mathrm{kg}$ of cheese $)$ & $0.57 \pm 0.05$ & $1.40 \pm 0.06$ & $1.21 \pm 0.03$ &
\end{tabular}

${ }^{1} \mathrm{FDM}=$ fat in DM; MNFS = moisture in nonfat substances; $\mathrm{S} / \mathrm{M}=$ salt in moisture. 

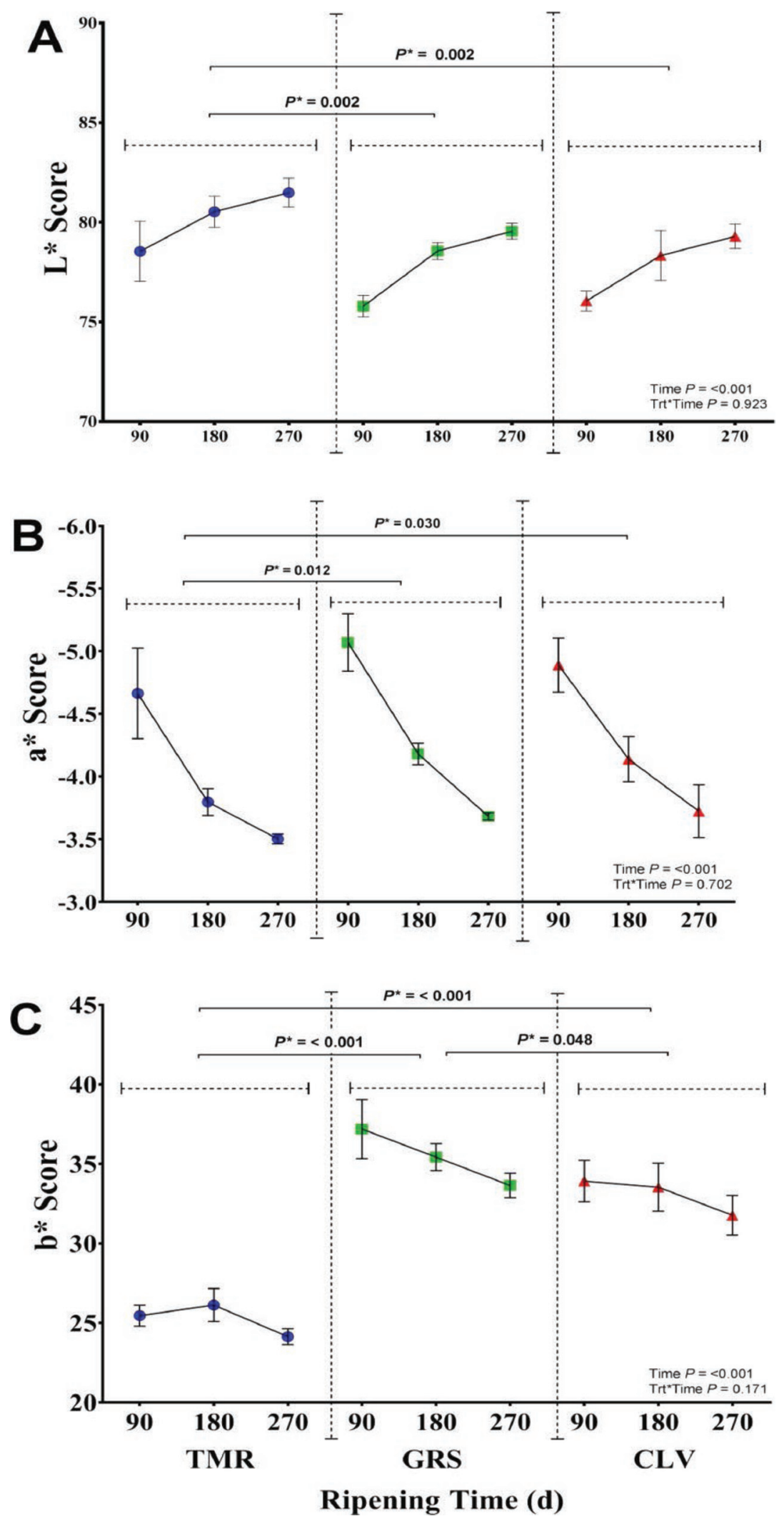

Figure 1. Color measurements (mean \pm SD) of Cheddar cheeses derived from different feeding systems: TMR $(\bullet)$, perennial ryegrass $($ GRS ) and perennial ryegrass and white clover $(\mathrm{CLV} ; \mathbf{\Lambda})$ throughout ripening for $270 \mathrm{~d}$ according to $\mathrm{L}^{*}, \mathrm{a}^{*}$ and $\mathrm{b}^{*}$ scale. $P^{*}$ denotes treatment $($ Trt $)$ significant effects. Color version available online. 
ing. However, a significant increase in \%pH 4.6-SN/ $\mathrm{TN}$ was recorded for all cheeses as ripening progressed. For all cheeses, $\% \mathrm{pH}$ 4.6-SN/TN increased from, on average, $12.31 \pm 0.92$ to $21.94 \pm 0.43 \%$ between 90 and $270 \mathrm{~d}$ of ripening $(P<0.001$; Supplementary Figure S1; https://doi.org/10.3168/jds.2016-12508). The increasing trend in $\% \mathrm{pH} 4.6-\mathrm{SN} / \mathrm{TN}$ over ripening is similar to that of other Cheddar cheese studies (Hickey et al., 2006, 2007; Hou et al., 2012). The increase in $\% \mathrm{pH} 4.6-\mathrm{SN} / \mathrm{TN}$ over ripening has been attributed to the breakdown of intact casein proteins, primarily by the action of residual chymosin, proteinase enzymes, and the proteolytic activity of starter cultures (Sousa et al., 2001). Proteolysis during ripening of cheeses can have a significant effect on several cheese attributes, including development of texture and flavor (Fenelon et al., 2000a; McSweeney and Sousa, 2000), which in turn can affect the overall acceptability of the cheeses. It was perhaps unsurprising that feeding system did not significantly affect the level of primary proteolysis in Cheddar cheeses, given the major differences from feeding regimen are associated with the fatty acid composition of milks in this study, rather than the proteins. Fenelon et al. (2000a) reported a difference in Cheddar cheese proteolysis with increasing fat contents of Cheddar cheeses and this was primarily attributed to an increased protein content with concomitant decrease in fat content.

Total and Free AA Analysis. The effects of feeding system on the total free AA (TFAA) throughout ripening is shown in Figure 2A. Feeding systems did not have a significant effect on TFAA or individual FAA content throughout ripening. A significant increase in the TFAA $(P<0.001)$ during $270 \mathrm{~d}$ of ripening was observed. Between 90 and $270 \mathrm{~d}$ of ripening, TFAA increased from $14,172 \pm 2,490$ to $32,893 \pm 1,179 \mathrm{mg} /$ $\mathrm{kg}$ of cheese. The concentrations of individual FAA after 90 and $270 \mathrm{~d}$ of ripening are shown in Figure 2B and Figure 2C, respectively. Increased levels of FAA in cheeses throughout ripening has been attributed to the peptidase activity of lactic acid bacteria, particularly Lactobacillus. Hydrolysis of casein during primary proteolysis results in the release of peptides that are subsequently hydrolyzed by intracellular peptidases of Lactobacillus (Khalid and Marth, 1990; Fox and McSweeney, 1996). Free amino acids produced during this process have a significant effect on the subsequent development of flavor properties in cheeses (McSweeney and Sousa, 2000).

\section{Cheese Fatty Acid Composition}

Table 2 shows the triglyceride composition of the cheeses after $90 \mathrm{~d}$ of ripening. Feeding system had a significant effect on cheese triglyceride content. Such differences between feeding systems followed similar trends to that of the raw milks from these diets previously reported (O'Callaghan et al., 2016b). Indeed, Coakley et al. (2007) and Lucas et al. (2006) reported that the cheese-making process has little effect on the triglyceride composition of cheeses. Among the major FA, TMR-derived cheeses had a significantly higher content of palmitic acid (C16:0) compared with GRS$(P=0.025)$ and CLV- $(P=0.014)$ derived cheeses. The pasture-derived cheeses had significantly higher vaccenic acid (VA) content (C18:1 trans-11) than the TMR cheeses with a $>1.8$-fold increase in VA $(P<0.001)$, whereas the VA content did not differ between GRS and CLV cheeses. Pasture-derived cheeses had significantly higher $(P<0.001)$ concentrations of linoelaidic acid (C18:2n-6 trans) than did TMR-derived cheese. Total mixed ration Cheddar cheese had significantly higher content of linoleic acid (C18:2n-6 cis) than did CLV ( $P$ $<0.001)$ or GRS $(P<0.001)$ cheese, and the linoleic acid content was significantly higher in CLV than in GRS $(P=0.034)$ cheese. The concentration of the CLA c9t11 was significantly higher in pasture-derived cheese than TMR-derived cheese and was present at highest concentrations in GRS cheese, which was significantly higher than $\operatorname{CLV}(P=0.015)$ and TMR $(P \leq 0.001)$ cheeses. The GRS and CLV cheeses had significantly higher $\alpha$-linolenic acid and arachidonic acid contents compared with TMR cheese. Similar to the milk from this study, the pasture-derived cheese had greater than 3 times more $\alpha$-linolenic acid than those from TMR cheese. Similar effects of TMR or pasture feeding systems on the $\alpha$-linolenic acid content of milk have been reported in the past (White et al., 2001; Ellis et al., 2006). Romanzin et al. (2013) reported that mountain pastures yielded cheeses with increased $\alpha$-linolenic acid content compared with indoor feeding systems. Increased $\alpha$-linolenic acid content of CLV-derived products over GRS $(P=0.005)$ could result from the higher intake and ruminal passage rates of $\alpha$-linolenic acid, in turn supplying a higher portion of the fatty acid for absorption (van Dorland et al., 2008).

These differences in the FA contents of cheeses resulted in significant differences in the health indices of FA. The thrombogenicity score for TMR cheese was significantly higher than that of GRS $(P=0.006)$ and CLV $(P=0.002)$ cheeses.

The GRS and CLV feeding systems resulted in a 2.9- and 2.3-fold increase in CLA c9t11 concentrations, respectively, compared with the TMR feeding system. Increases in CLA c9t11 of a similar magnitude were also reported by Romanzin et al. (2013), who compared the effect of mountain pastures versus indoor feeding systems on Montasio cheese. Although the CLA con- 

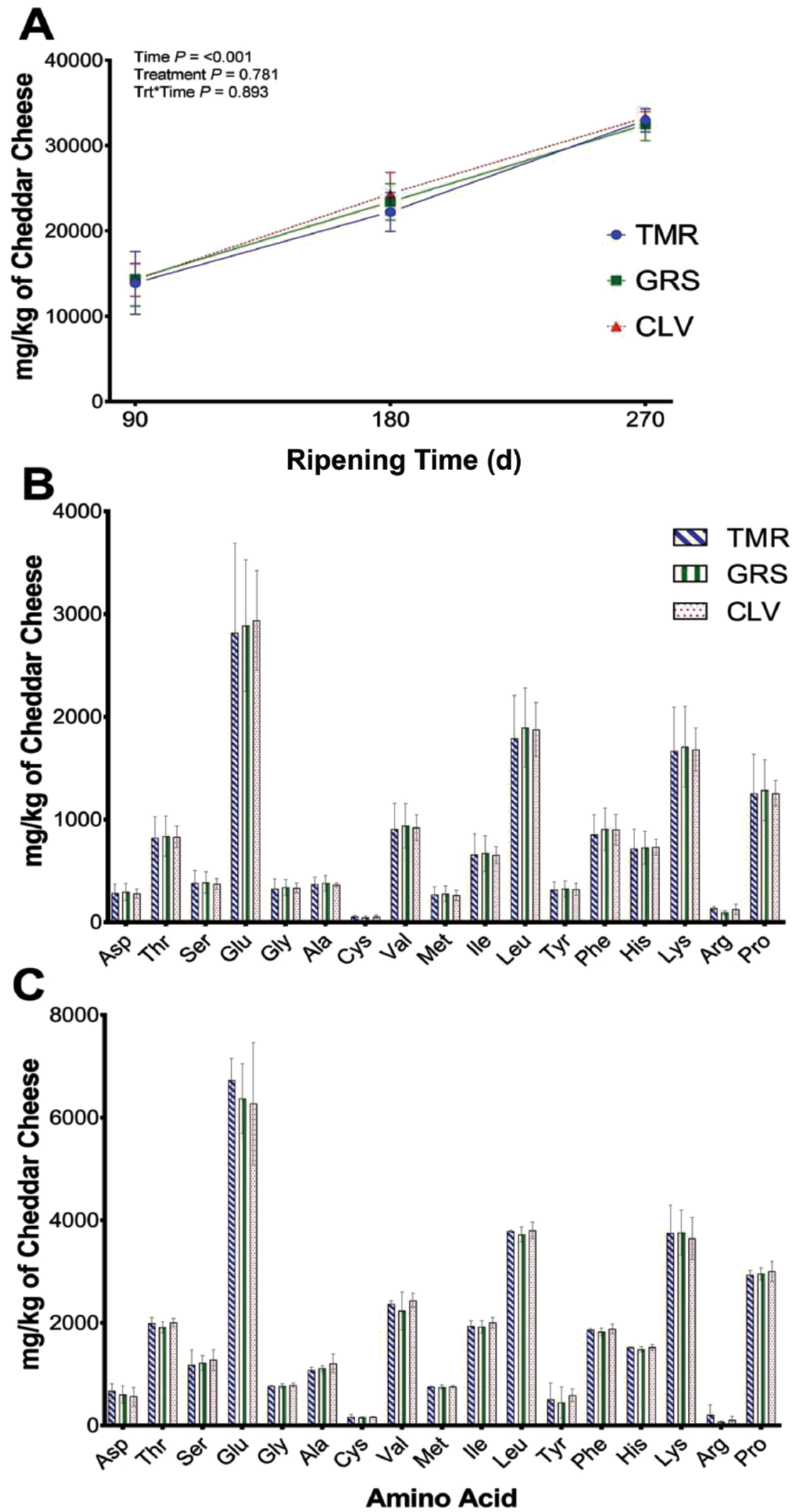

Figure 2. (A) Total free AA content in Cheddar cheeses derived from different cow feeding systems: TMR (๑), perennial ryegrass (GRS; and perennial ryegrass and white clover $(\mathrm{CLV} ; \mathbf{\Delta})$ throughout ripening for $270 \mathrm{~d}$. Free AA profile of Cheddar cheeses at $90 \mathrm{~d}(\mathrm{~B})$ of ripening and $270 \mathrm{~d}(\mathrm{C})$ of ripening $($ mean $\pm \mathrm{SD})$. Trt $=$ treatment. Color version available online. 
Table 2. Mean fatty acid triglyceride (g/100 g of cheese fat; mean \pm SD) contents of Cheddar cheeses derived from TMR, perennial ryegrass (GRS), and perennial ryegrass and white clover (CLV) feeding systems ${ }^{1}$

\begin{tabular}{|c|c|c|c|c|}
\hline Fatty acid triglycerides ${ }^{2}$ & TMR & GRS & CLV & Treatment \\
\hline Butyric acid (C4:0) & $3.59 \pm 0.15$ & $3.58 \pm 0.14$ & $3.68 \pm 0.14$ & 0.768 \\
\hline Caproic acid (C6:0) & $1.96 \pm 0.06$ & $1.88 \pm 0.04$ & $1.93 \pm 0.07$ & 0.415 \\
\hline Caprylic acid (C8:0) & $1.09 \pm 0.03$ & $1.03 \pm 0.02$ & $1.07 \pm 0.04$ & 0.297 \\
\hline Capric acid (C10:0) & $2.41 \pm 0.06$ & $2.26 \pm 0.05$ & $2.35 \pm 0.08$ & 0.166 \\
\hline Undecanoic acid (C11:0) & $0.04 \pm 0.00$ & $0.04 \pm 0.00$ & $0.03 \pm 0.00$ & 0.013 \\
\hline Lauric acid (C12:0) & $2.79 \pm 0.06$ & $2.63 \pm 0.07$ & $2.71 \pm 0.09$ & 0.152 \\
\hline Tridecanoic acid (C13:0) & $0.07 \pm 0.00$ & $0.06 \pm 0.01$ & $0.05 \pm 0.00$ & 0.014 \\
\hline Myristic acid (C14:0) & $8.72 \pm 0.35$ & $8.80 \pm 0.22$ & $7.55 \pm 2.27$ & 0.599 \\
\hline Myristoleic acid (C14:1) & $0.93 \pm 0.01$ & $1.01 \pm 0.02$ & $0.94 \pm 0.03$ & 0.021 \\
\hline Pentadecanoic acid (C15:0) & $0.83 \pm 0.02$ & $1.00 \pm 0.03$ & $0.94 \pm 0.04$ & 0.004 \\
\hline Palmitic acid (C16:0) & $26.62 \pm 0.83$ & $23.27 \pm 0.66$ & $22.80 \pm 1.19$ & 0.012 \\
\hline Palmitoleic acid (C16:1) & $1.43 \pm 0.04$ & $1.39 \pm 0.04$ & $1.29 \pm 0.06$ & 0.091 \\
\hline Heptadecanoic acid (C17:0) & $0.52 \pm 0.02$ & $0.61 \pm 0.04$ & $0.61 \pm 0.02$ & 0.042 \\
\hline Stearic acid $(\mathrm{C} 18: 0)$ & $6.15 \pm 0.48$ & $6.97 \pm 0.92$ & $7.37 \pm 0.69$ & 0.300 \\
\hline Vaccenic acid (C18:1 trans-11) & $1.43 \pm 0.11$ & $3.23 \pm 0.26$ & $2.74 \pm 0.18$ & $<0.001$ \\
\hline Oleic acid $(\mathrm{C} 18: 1 \mathrm{n}-9 \mathrm{cis})$ & $13.78 \pm 0.53$ & $14.23 \pm 1.70$ & $14.49 \pm 1.17$ & 0.843 \\
\hline Linolelaidic acid (C18:2n-6 trans) & $0.15 \pm 0.01$ & $0.36 \pm 0.03$ & $0.42 \pm 0.02$ & $<0.001$ \\
\hline Linoleic acid (C18:2n-6 cis) & $1.45 \pm 0.09$ & $0.49 \pm 0.04$ & $0.69 \pm 0.03$ & $<0.001$ \\
\hline$\alpha$-Linolenic acid (C18:3n-3) & $0.26 \pm 0.03$ & $0.62 \pm 0.09$ & $0.98 \pm 0.08$ & $<0.001$ \\
\hline CLA (cis-9,trans-11) & $0.49 \pm 0.02$ & $1.45 \pm 0.12$ & $1.13 \pm 0.06$ & $<0.001$ \\
\hline CLA (trans-10,cis-12) & $0.11 \pm 0.00$ & $0.10 \pm 0.01$ & $0.10 \pm 0.00$ & 0.579 \\
\hline Eicosenoic acid (C20:1) & $0.02 \pm 0.01$ & $0.07 \pm 0.01$ & $0.08 \pm 0.01$ & 0.003 \\
\hline Eicosatrienoic acid (C20:3n-6) & $0.08 \pm 0.01$ & $0.01 \pm 0.01$ & $0.03 \pm 0.00$ & 0.001 \\
\hline Behenic acid (C22:0) & $0.02 \pm 0.00$ & $0.03 \pm 0.01$ & $0.03 \pm 0.00$ & 0.309 \\
\hline Erucic acid (C22:1n-9) & $0.05 \pm 0.00$ & $0.02 \pm 0.00$ & $0.03 \pm 0.00$ & $<0.001$ \\
\hline Tricosanoic acid (C23:0) & $0.01 \pm 0.01$ & $0.10 \pm 0.01$ & $0.11 \pm 0.01$ & $<0.001$ \\
\hline Arachidonic acid (C20:4n-6) & $0.00 \pm 0.00$ & $0.05 \pm 0.01$ & $0.06 \pm 0.00$ & $<0.001$ \\
\hline SFA & $54.82 \pm 2.28$ & $52.28 \pm 2.18$ & $52.66 \pm 1.86$ & 0.350 \\
\hline UFA & $20.16 \pm 0.83$ & $23.04 \pm 2.31$ & $22.98 \pm 1.66$ & 0.196 \\
\hline MUFA & $17.63 \pm 0.69$ & $19.95 \pm 2.04$ & $19.57 \pm 1.46$ & 0.275 \\
\hline PUFA & $2.54 \pm 0.15$ & $3.14 \pm 0.29$ & $3.47 \pm 0.20$ & 0.011 \\
\hline Short-chain (C4-14) & $21.59 \pm 0.81$ & $21.30 \pm 0.90$ & $21.75 \pm 0.75$ & 0.791 \\
\hline Medium-chain (C15-17) & $29.40 \pm 0.99$ & $26.28 \pm 1.10$ & $25.63 \pm 1.31$ & 0.017 \\
\hline Long-chain (C18-24) & $24.00 \pm 1.33$ & $27.74 \pm 3.18$ & $28.25 \pm 2.46$ & 0.208 \\
\hline$n-3$ & $0.26 \pm 0.03$ & $0.62 \pm 0.09$ & $0.98 \pm 0.09$ & $<0.001$ \\
\hline$n-6$ & $1.68 \pm 0.11$ & $0.91 \pm 0.09$ & $1.19 \pm 0.07$ & $<0.001$ \\
\hline n-9 & $13.83 \pm 0.62$ & $14.25 \pm 1.78$ & $14.52 \pm 1.31$ & 0.856 \\
\hline $\mathrm{n}-3 / \mathrm{n}-6$ & $0.16 \pm 0.01$ & $0.68 \pm 0.03$ & $0.82 \pm 0.04$ & $<0.001$ \\
\hline Hardness index (C18:1n-9 cis/C16:0) & $0.52 \pm 0.01$ & $0.61 \pm 0.08$ & $0.64 \pm 0.08$ & 0.221 \\
\hline Atherogenicity index & $3.29 \pm 0.04$ & $2.87 \pm 0.27$ & $2.84 \pm 0.23$ & 0.119 \\
\hline Thrombogenicity index & $3.92 \pm 0.05$ & $3.03 \pm 0.24$ & $2.78 \pm 0.19$ & 0.002 \\
\hline
\end{tabular}

${ }^{1}$ Statistical analysis by one-way ANOVA with post hoc Tukey test.

${ }^{2} \mathrm{n}-3=$ sum of $\alpha$-linolenic acid (ALA), n-6 = sum of linolelaidic acid, linoleic acid (LA), $\gamma$-linoleic acid, eicosatrienoic acid and arachidonic acid; n-9 = sum of oleic acid and erucic acid.

centration in TMR-derived cheese in the current study was similar to that reported by Coakley et al. (2007), in the earlier study, supplementation of pasture-fed cows with sunflower oil resulted in Cheddar cheese with a higher mean CLA c9t11 content compared with the pasture-only cows used in this study. The consumption of CLA has been associated with several potential health benefits and, as a result, Siurana and Calsamiglia (2016) recommended an intake between 0.8 and $3.2 \mathrm{~g}$ of CLA/d to attain such benefits based on animal models of therapeutic doses. Adjusting for the mean fat contents of cheeses in this study (Table 1), $100 \mathrm{~g}$ of Cheddar cheese from TMR feeding system would provide $0.15 \mathrm{~g}$ of CLA c9t11, $100 \mathrm{~g}$ of CLV cheese would provide $0.35 \mathrm{~g}$ of CLA c9t11, whereas $100 \mathrm{~g}$ of
GRS-derived Cheddar cheese from this study would provide $0.44 \mathrm{~g}$ of CLA c9t11. Therefore, the quantities needed to reach the minimum required CLA intake (0.8 $\mathrm{g} / \mathrm{d}$ ) would be much less from GRS and CLV cheeses than from TMR cheese (mean \pm SD; $181.54 \pm 14.49$ g, $226.47 \pm 12.38 \mathrm{~g}$, and $531.53 \pm 22.37 \mathrm{~g}$ of Cheddar cheese, respectively).

Partial least squares regression analysis of triglyceride data from cheeses showed complete separation of TMR and pasture cheeses based on their FA profile (Figure 3). The GRS- and CLV-derived cheeses are separated to the left (negative) side of the plot and associated with contents of CLA c9t11, VA, arachidonic acid, linoelaidic acid, $\alpha$-linolenic acid, tricosanoic acid, pentadecanoic acid, eicosanoic acid, and n-3 FA 
content. The TMR cheese was separated to the right (positive) side of the plot and was correlated with contents of palmitic acid, erucic acid, eicosatrienoic acid, tridecanoic acid, undecanoic acid, linoleic acid, higher atherogenicity and thrombogenicity scores, and n-6 FA content, which are in agreement with data in Table 2. Similar plots were reported for the butter and raw milks from these diets (O'Callaghan et al., 2016a,b), which further highlights the relevance of FA profile for distinguishing between pasture-based and conventional TMR feeding systems.

The average FFA contents of cheeses throughout ripening are shown in Table 3. Ripening period had a significant effect on the total FFA content of cheeses, which increased from $\sim 982 \mathrm{mg} / \mathrm{kg}$ of cheese after 90 $\mathrm{d}$ of ripening to $\sim 1,342 \mathrm{mg} / \mathrm{kg}$ after $270 \mathrm{~d}$ of ripening (Table 3). Hickey et al. (2006) concluded that starter bacteria are the major causative agents of lipolysis in Cheddar cheeses from pasteurized milk. Although the FFA produced via lipolysis can have a direct effect on cheese flavor, FFA are further metabolized to volatile compounds also capable of affecting cheese flavor, such as methyl ketones, lactones, esters, and secondary alcohols (Collins et al., 2003).

\section{Texture Analysis}

At Room Temperature. Feeding system had a significant effect $(P<0.05)$ on the texture of cheeses at room temperature; values are summarized in Table 4. The TMR cheeses were significantly harder than GRS $(P=0.013)$ and $\operatorname{CLV}(P=0.026)$ cheeses, with hardness scores of $154.20 \pm 10.08,111.50 \pm 4.17$, and $117.61 \pm 13.68 \mathrm{~N}$, respectively. We detected no significant difference in hardness between GRS and CLV cheeses. Feeding system did not affect the cohesiveness attribute of cheese textures at room temperature. The CLV-derived cheese had the lowest springiness values at $5.76 \pm 0.13 \mathrm{~mm}$, which was significantly $(P=0.017)$ lower than that of GRS-derived cheese at $6.32 \pm 0.15$ $\mathrm{mm}$. The TMR cheese had significantly higher $(P=$ 0.002) chewiness values than those of GRS and CLV at $436.46 \pm 19.93,311.97 \pm 22.48$, and $277.39 \pm 19.17 \mathrm{~J}$, respectively. At room temperature, hardness of cheeses was significantly correlated with the chewiness attribute $(P=0.002 ; \mathrm{r}=0.879)$.

At Refrigeration Temperature. Feeding system did not have a significant effect on the hardness, cohesiveness, or chewiness attributes of Cheddar cheeses at refrigeration temperature. However, the springiness attribute of TMR was significantly higher $(P=0.024)$ than CLV cheese. Significant differences in cheese texture were observed as ripening progressed (Table 4). The hardness of each of the cheeses decreased signifi- cantly $(P=0.026)$ between 90 and $270 \mathrm{~d}$ of ripening by $\sim 19.14 \%$. The cohesiveness of cheeses decreased significantly $(P<0.001)$ between 90 and $270 \mathrm{~d}$ of ripening by $\sim 23.08 \%$. The springiness attribute of the cheeses was significantly $(P<0.001)$ reduced (by $12.28 \%)$ between 90 and $270 \mathrm{~d}$ of ripening. Ripening time resulted in a $44.93 \%$ reduction $(P<0.001)$ in the chewiness attribute of cheeses. At refrigerated temperature, among the textural attributes, hardness was significantly correlated with chewiness $(P<0.001 ; \mathrm{r}=0.897)$. Cohesiveness was also significantly correlated with chewiness $(P<0.001 ; \mathrm{r}=0.859)$ and springiness was significantly correlated with the chewiness $(P<0.001 ; \mathrm{r}=0.906)$ of cheeses.

A decline in textural attributes of Cheddar cheeses during ripening has been widely reported and has been attributed to the levels of intact casein proteins because of primary proteolysis (Fox, 1989; Fenelon and Guinee, 2000; O'Mahony et al., 2005). In the current study, levels of $\mathrm{pH} 4.6-\mathrm{SN} / \mathrm{TN}$ were significantly and negatively associated with each textural attribute; hardness $(P=0.001 ; \mathrm{r}=-0.720)$, cohesiveness $(P<0.001 ; \mathrm{r}$ $=-0.897)$, and chewiness $(P<0.001 ; \mathrm{r}=-0.906)$ throughout ripening.

Overall, our results have shown that GRS- and CLVderived milks yield cheeses that are less firm at room temperature than TMR-derived cheese milks. Even though not statistically significant, the mean hardness values of TMR cheeses were higher than those of pasture-derived cheeses at refrigerated temperatures. Similar results were reported by Coppa et al. (2011), who investigated the effects of hay and concentrate or grazing-based diets on texture of Cantal cheeses and reported that the pasture-based cheeses were less firm than the hay-derived cheeses. The FA composition of the cheeses can have a significant effect on cheese texture, particularly at room temperature. Palmitic and oleic acids are the principal SFA and UFA in dairy products with high and low melting points, respectively. The ratio of oleic acid to palmitic acid has previously been used as an index of hardness in dairy products (Martin et al., 2005). Indeed, Coppa et al. (2011) reported that the higher ratio of oleic to palmitic acid in milk was related to a less firm cheese. Our study reports similar results where the oleic-to-palmitic acid ratio was negatively correlated with cheese hardness $(P=0.031$; $\mathrm{r}=-0.714)$ and chewiness $(P=0.024 ; \mathrm{r}=-0.735)$. The increased hardness of TMR-derived cheese could be attributed to the significantly higher concentration of palmitic acid, which has a higher melting point than that of UFA, resulting in a more solid fat at room temperature. Indeed, palmitic acid was significantly and positively correlated with hardness and chewiness attributes $(P=0.005 ; \mathrm{r}=0.836$ and $P=0,007 ; \mathrm{r}=$ 
O'CALLAGHAN ET AL.

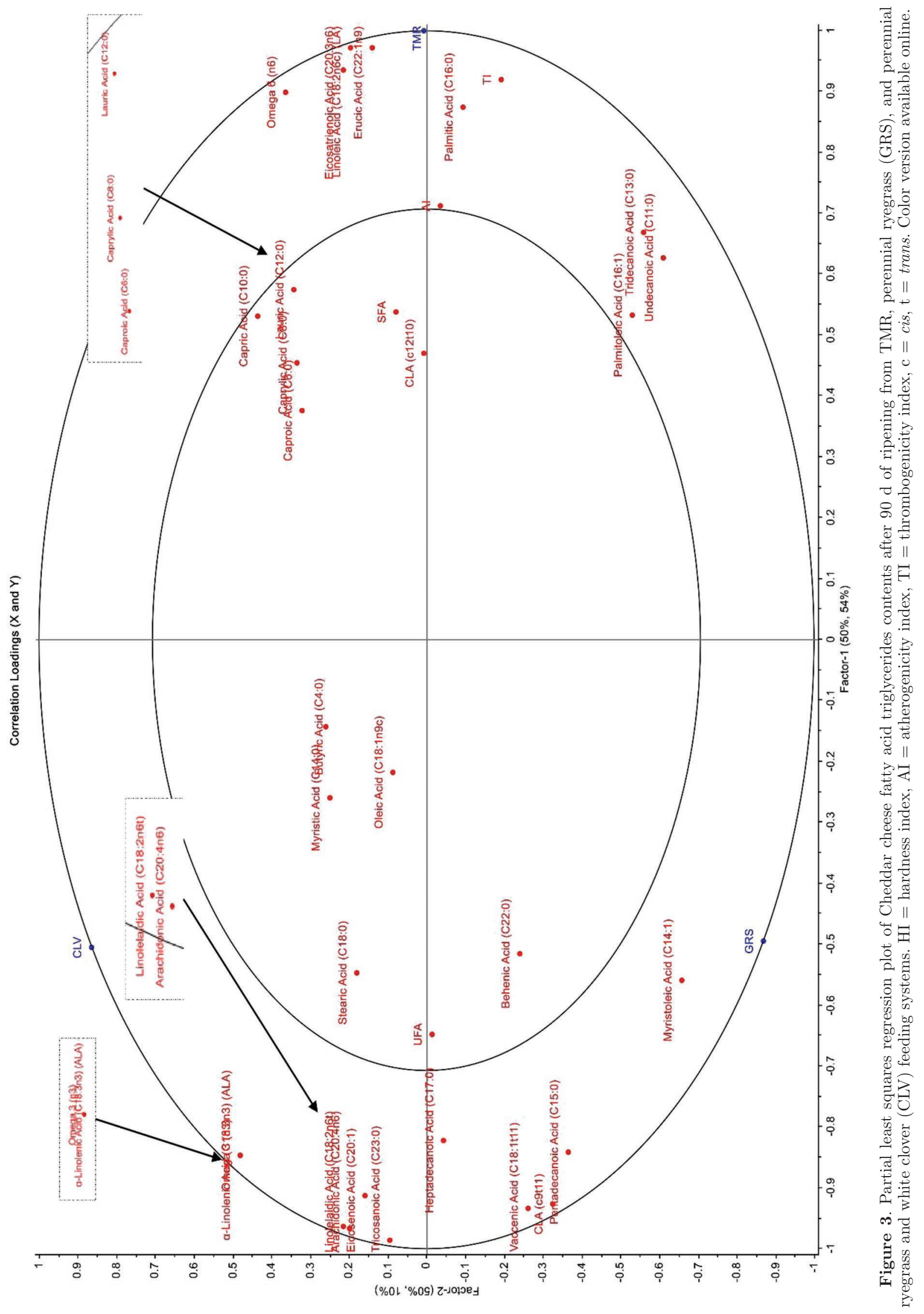

Journal of Dairy Science Vol. 100 No. 8, 2017 


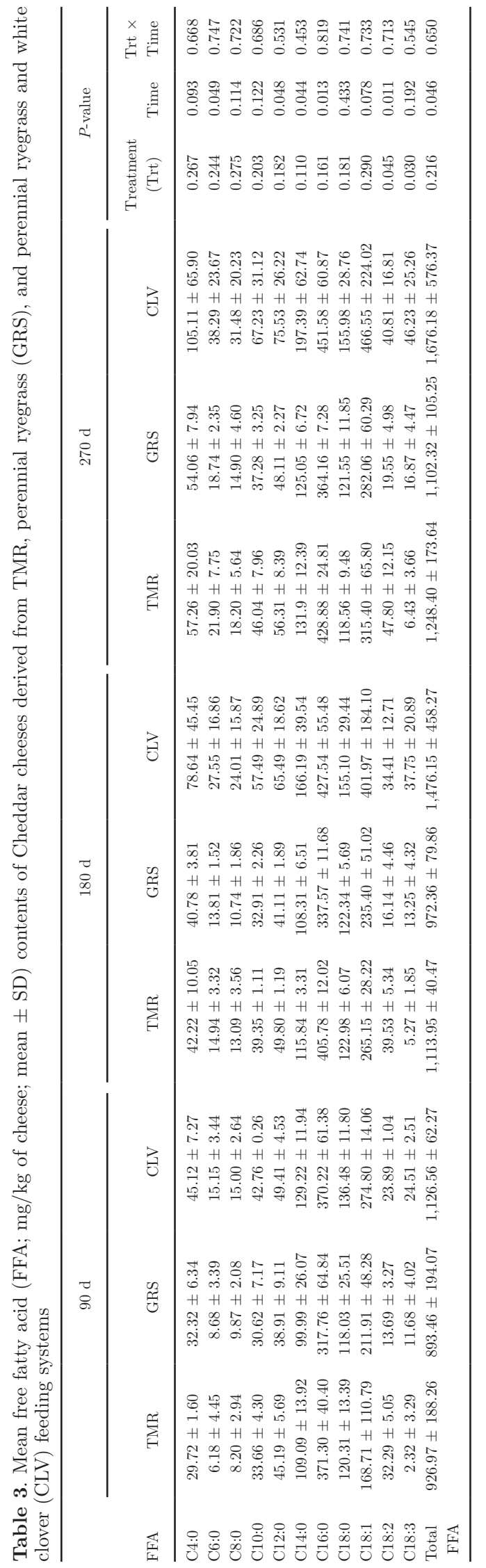

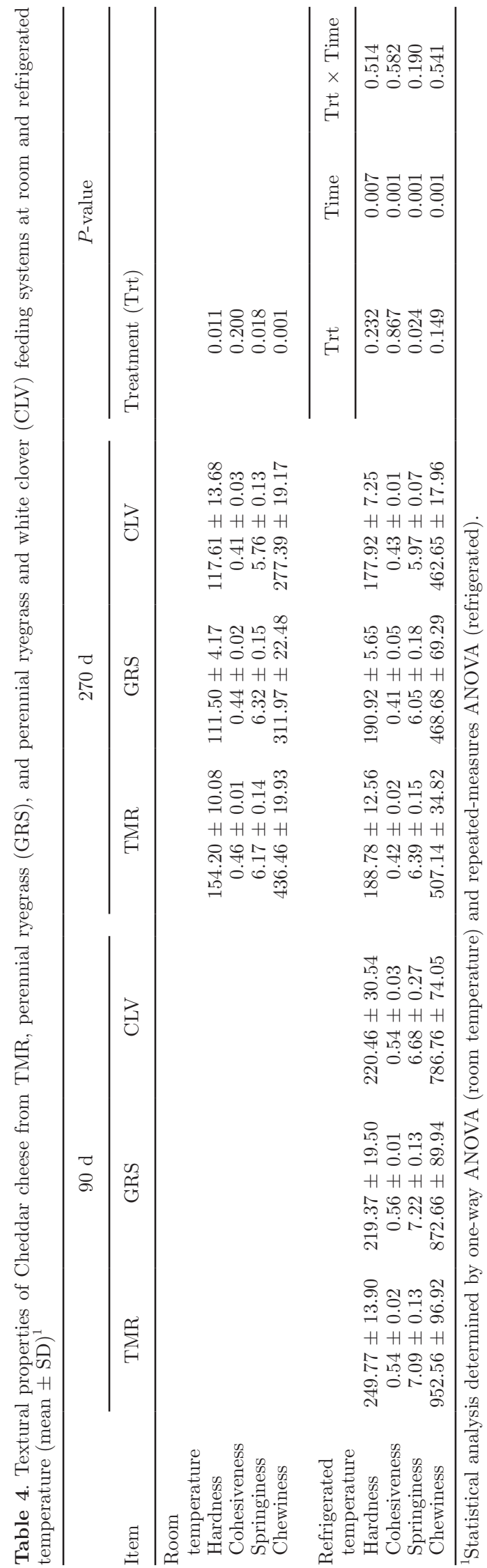




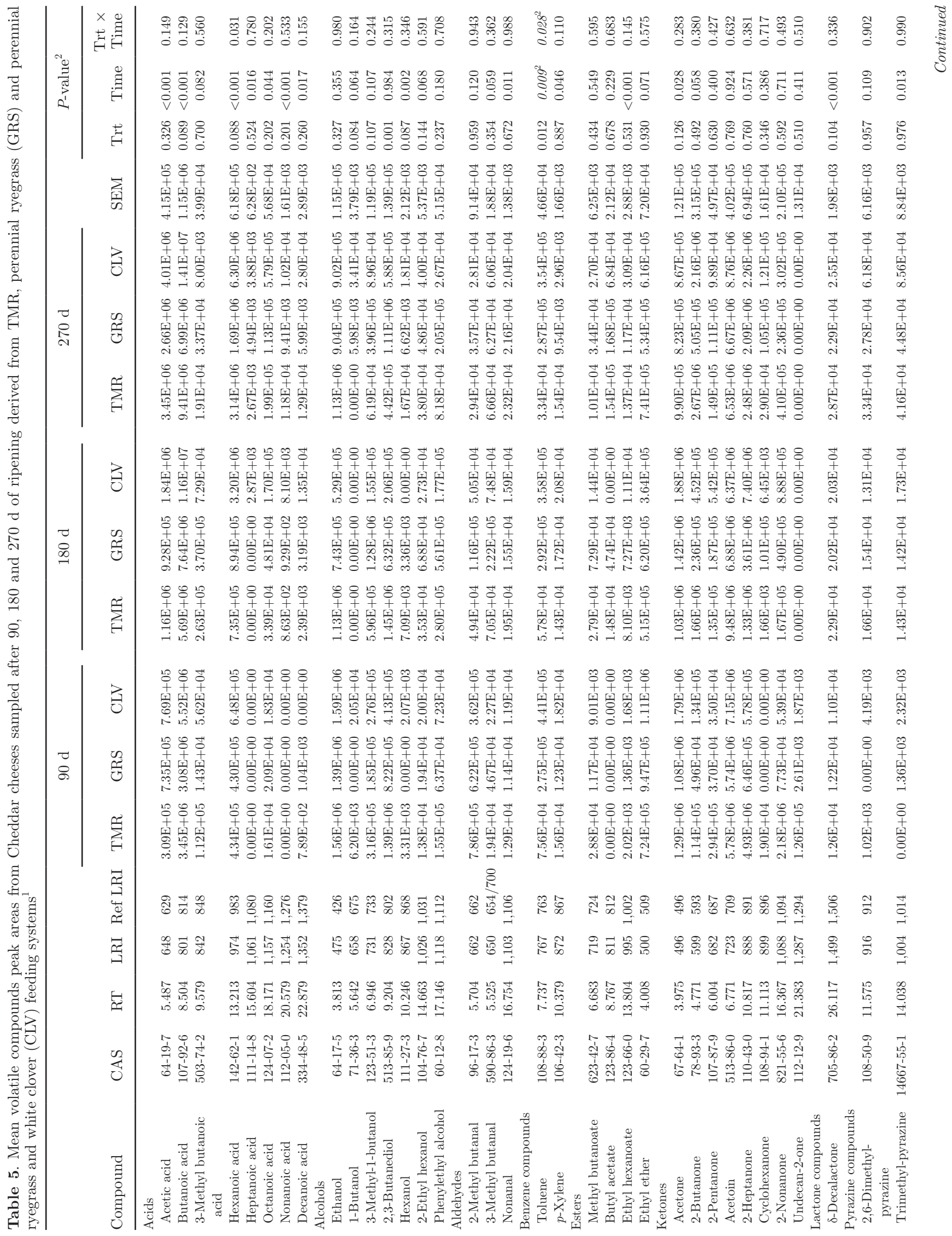


0.816 respectively). The increased CLA content of the pasture-derived cheese was also negatively correlated with hardness $(P=0.002 ; \mathrm{r}=0.877)$, and chewiness $(P$ $=0.004 ; \mathrm{r}=-0.849)$.

\section{Volatiles Analysis of Cheddar Cheeses}

Headspace analysis of cheeses in this study identified 39 volatile compounds, including 8 acids, 7 alcohols, 3 aldehydes, 2 benzene compounds, 4 esters, 9 ketones, 2 pyrazine compounds, 3 sulfur compounds, and 1 terpene compound. Table 5 shows the mean volatile composition of cheeses throughout the 270-d ripening period. The GRS- and CLV-derived Cheddar cheeses had a significantly higher concentration of toluene (nutty, bitter, almond odor) than that of TMR $(P=$ 0.028 and $P=0.015$, respectively). However, TMRderived cheese had a significantly higher concentration of 2,3-butanediol (fruity aroma, creamy buttery aroma) than did GRS- $(P=0.048)$ and CLV- $(P=0.001)$ derived cheeses, whereas the content of this compound was significantly higher in GRS- than in CLV-derived cheese $(P=0.003)$. Toluene is believed to be present as a product of $\beta$-carotene oxidation (Daun, 2005) and 2,3-butanediol has been reported previously as a product of citrate metabolism (Hassan et al., 2013).

Principal component analysis of volatile compound data throughout ripening (Figure 4) shows separation of the cheeses between stages of ripening. Ripening time appeared to have a significant effect on the volatile composition of the cheeses, as expected. In particular, ripening period resulted in a significant increase in acids, alcohols, aldehydes, esters, and terpene-based compounds, as shown in Table 5. Several volatile compounds appeared to be significantly correlated with changes in the chemical composition of cheeses throughout ripening (Table 6). The major attributes of cheese composition that appeared to affect the volatile profile of Cheddar cheeses were the levels of proteolysis, FAA, and FFA, and all are reported to affect the volatile profile of Cheddar cheese. Review of this topic by Singh et al. (2003) discusses how catabolism of FFA contributes volatile compounds, such as methyl ketones, keto acids, and lactones, whereas proteolysis and catabolism of FAA contributes amines, aldehydes, alcohols, pyruvate, ammonia, and sulfurbased volatile compounds to cheese flavor. Acidic compounds are typically derived from lipolysis, proteolysis, and carbohydrate metabolism. De Wit et al. (2005) reported that the principal VFA present in cheese during ripening include acetic, propionic, butanoic, pentanoic, and hexanoic acids. Ripening in this study resulted in a significant increase in acidic compounds, acetic acid (vinegar), butanoic acid (sweaty, butter, 
O'CALLAGHAN ET AL.

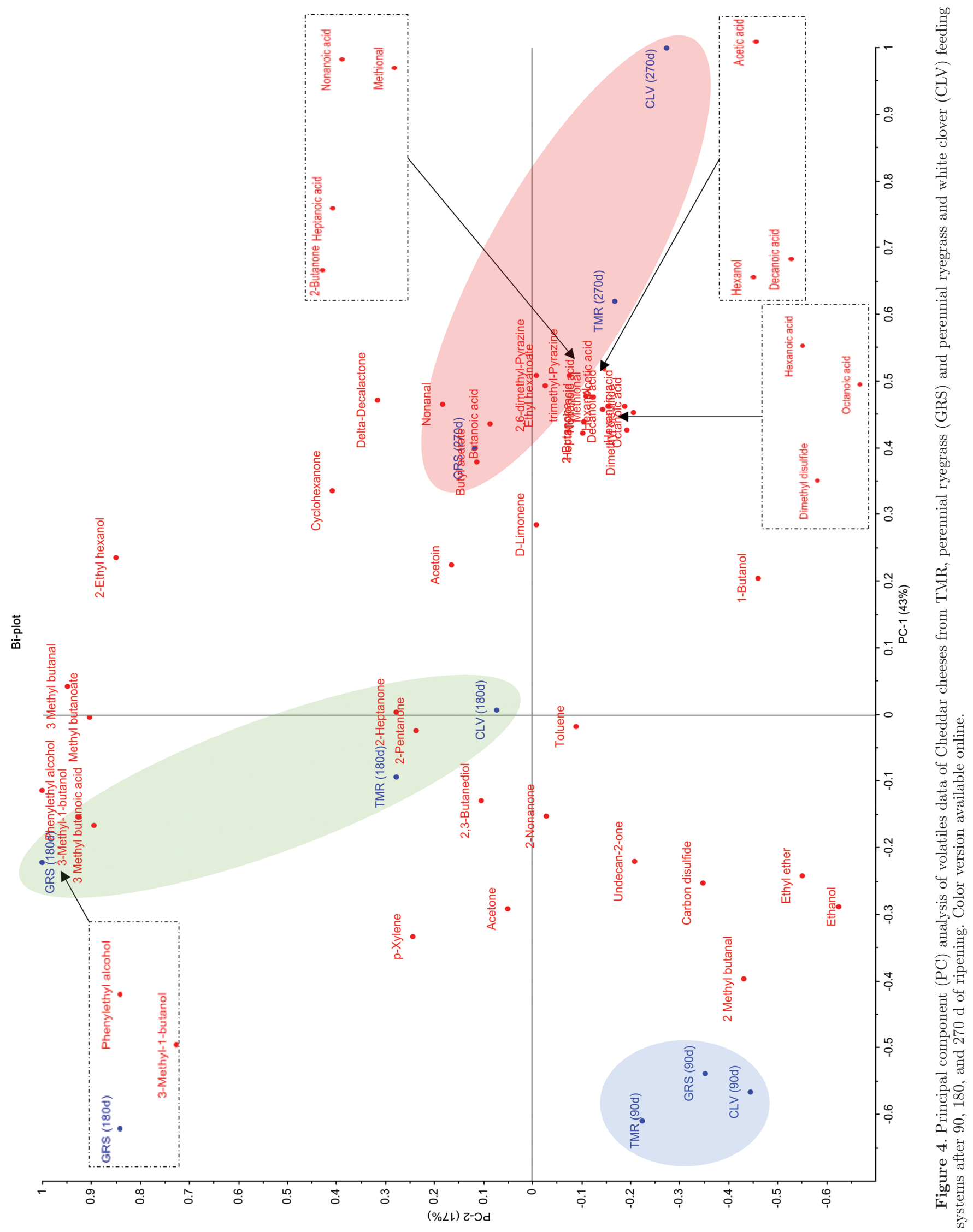

Journal of Dairy Science Vol. 100 No. 8, 2017 
Table 6. Significantly positive Pearson correlation analysis coefficients of volatile compounds analysis and Cheddar cheese chemical analysis over ripening

\begin{tabular}{|c|c|c|}
\hline Volatile compound & Odor description $^{1}$ & Pearson correlation analysis ${ }^{2}$ \\
\hline 2-Pentanone & Orange peel, sweet, fruity ${ }^{\mathrm{a}}$ & TFFA $(P=0.031 ; \mathrm{r}=0.522)$ \\
\hline Dimethyl disulfide & Sulfurous, cabbage-like, sour ${ }^{\mathrm{a}}$ & Proteolysis $(P=0.015 ; \mathrm{r}=0.576)$ \\
\hline Butanoic acid & Sweaty, cheese, fecal, rancid, toasted cheese ${ }^{\mathrm{a}}$ & TFFA $(P<0.001 ; \mathrm{r}=0.896)$ \\
\hline 2-Heptanone & Fruity, fatty, spicy, herbaceous ${ }^{\mathrm{a}}$ & TFFA $(P=0.018 ; \mathrm{r}=0.566)$ \\
\hline Methional & Boiled or baked potato $^{a}$ & TFAA $(P=0.013 ; \mathrm{r}=0.587)$, proteolysis $(P=0.046 ; \mathrm{r}=0.489)$ \\
\hline 2-Nonanone & Malty, fruity, hot milk, smoked cheese ${ }^{\mathrm{a}}$ & TFFA $(P=0.021 ; \mathrm{r}=0.556)$ \\
\hline Octanoic acid & Sweat, fatty, rancid, pungent, cheese ${ }^{\mathrm{a}}$ & TFFA $(P<0.001 ; \mathrm{r}=0.832)$ \\
\hline Decanoic acid & Stale, butter, grassy, fatty, sour fruit, milk ${ }^{\mathrm{a}}$ & TFFA $(P<0.001 ; \mathrm{r}=0.882)$ \\
\hline
\end{tabular}

${ }^{1}$ Odor descriptor references: ${ }^{\mathrm{a}}$ Curioni and Bosset (2002).

${ }^{2} \mathrm{TFAA}=$ total free $\mathrm{AA} ; \mathrm{TFFA}=$ total free fatty acids; $\mathrm{b}^{*}$ value = yellow-blue color.

rancid), hexanoic acid (acidic, sweaty, cheesy), heptanoic acid (soapy, fatty), octanoic acid (pungent, waxy, cheesey), nonanoic acid (fatty, green, waxy), and decanoic acid (stale, butter, sour, fruit). Similar increases in acidic compounds of Cheddar cheeses over ripening was reported by Gan et al. (2016), who also reported that heptanoic and hexanoic acid were significant in predicting the maturity of Cheddar cheese. Similarly, hexanoic acid (treatment $\times$ time $P=0.031$ ) increased over ripening time in this study. Although the hexanoic acid content increased more in CLV than GRS $(P=$ $0.089)$ and TMR $(P=0.141)$ cheeses during ripening, we did not detect a significant overall treatment effect between feeding systems $(P=0.088)$. Hexanoic acid is a common volatile compound found in cheese and is a direct result of lipolysis of milk fat (Curioni and Bosset, 2002); indeed, hexanoic acid content was highly correlated with the total FFA content of the cheeses $(P<0.001 ; \mathrm{r}=0.891)$, and the significant treatment $\times$ time effect could be attributed to increased FFA in CLV cheeses. Heptanoic acid was not present in 90-d samples, was present only in CLV samples at 180d, and was detected in all cheese samples after $270 \mathrm{~d}$ of ripening. $\delta$-Decalactone (coconut-like, creamy, milk fat) also increased significantly in each of the cheeses throughout ripening. Lactone compounds are derived from hydroxylated fatty acids produced from heating, through the action of lipases, or by a one-step intermolecular transesterification reaction (Kilcawley, 2017). The terpene content of milks and dairy products are influenced by the feed source (Karoui and De Baerdemaeker, 2007); although D-limonene was the only terpene compound detected in each of the cheeses, ripening time resulted in a significant increase in its concentration. Aprea et al. (2016) also reported an increase in terpene content in Montasio cheeses over ripening, which could be attributed to the ability of lactic acid bacteria to modify and biosynthesize terpenoids (Belviso et al., 2011).

\section{Affective and Ranking Sensory Descriptive Analysis of Cheddar Cheeses}

Mean scores from sensory hedonic and RDA of cheeses after 180 and $270 \mathrm{~d}$ of ripening are summarized in Figure 5A and 5B, respectively. The CLV-derived cheeses after $180 \mathrm{~d}$ of ripening were positively associated with liking of appearance $(P=0.002)$ and overall acceptability $(P=0.048)$. Following $180 \mathrm{~d}$ of ripening, the TMR-derived cheese was positively associated with liking of texture $(P=0.027)$ and the scores for overall acceptability were positively associated with TMR cheeses $(P=0.052)$. The GRS-derived cheeses were negatively associated with liking of appearance $(P$ $=0.013$ ) after $270 \mathrm{~d}$ of ripening, and the CLV-derived cheese was negatively associated with liking of texture $(P=0.018)$ after $270 \mathrm{~d}$ of ripening.

The GRS-derived cheeses after $180 \mathrm{~d}$ of ripening were positively associated with color $(P<0.001)$ but negatively associated with sweet taste $(P=0.020)$. The CLV-derived cheeses after $180 \mathrm{~d}$ of ripening were found to be negatively associated with crumbly texture $(P=$ 0.026). The TMR-derived cheeses after $180 \mathrm{~d}$ of ripening were negatively associated with color $(P<0.001)$ but positively associated with fruity estery flavor $(P=$ 0.045). The GRS-derived cheeses after $270 \mathrm{~d}$ of ripening was also positively associated with color $(P<0.001)$ and salt taste $(P=0.024)$. The CLV-derived cheeses after $270 \mathrm{~d}$ of ripening were positively associated with color $(P=0.001)$ but negatively associated with sweet taste $(P=0.013)$. Finally, the TMR-derived cheeses 
after $270 \mathrm{~d}$ of ripening were negatively associated with color $(P<0.001)$ but positively associated with sour taste $(P=0.007)$. Although we detected no significant difference in FAA between feeding systems, principal component analysis of cheese FAA (Supplementary Figure S2; https://doi.org/10.3168/jds.2016-12508)

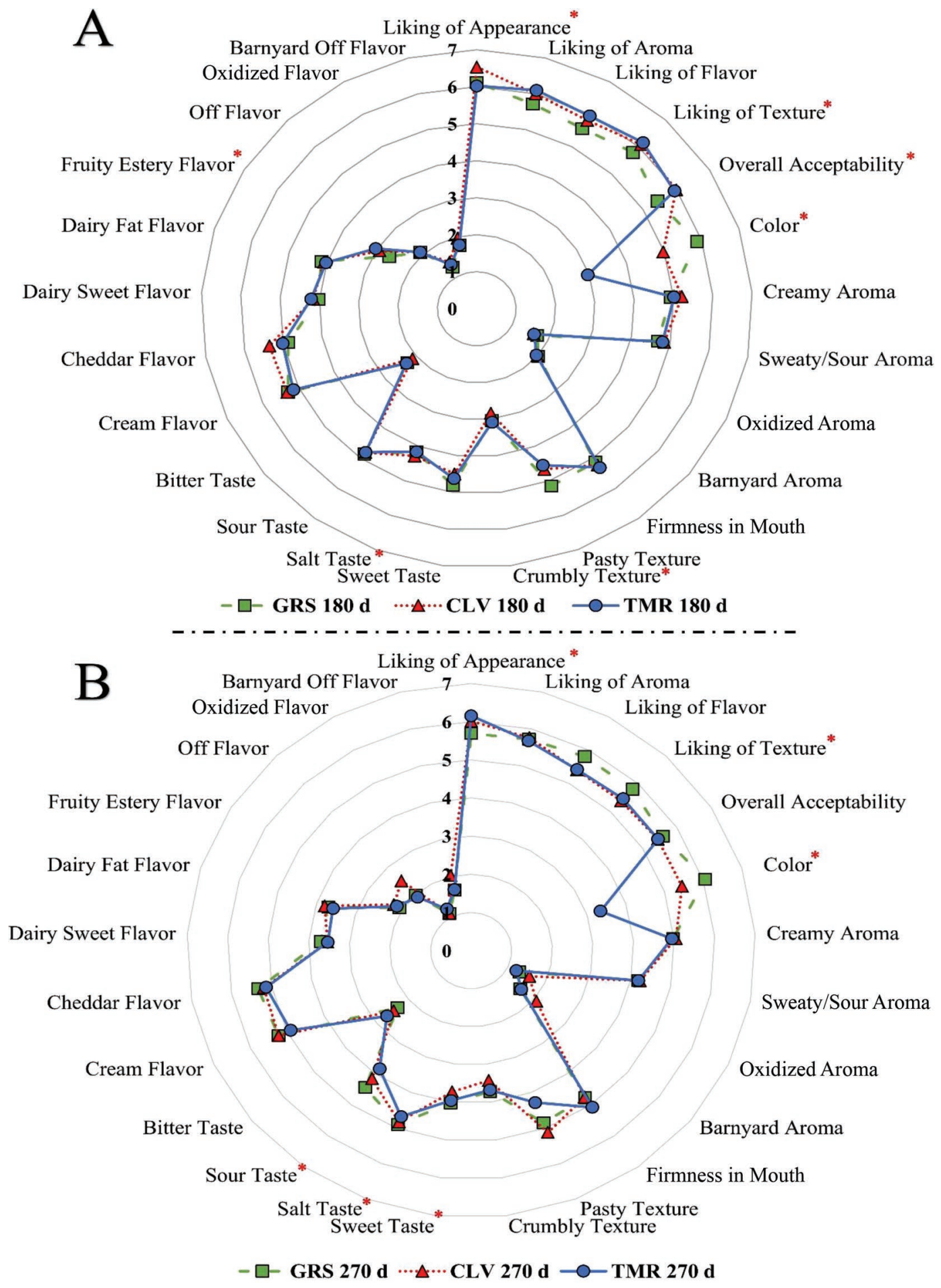

Figure 5. Mean sensory hedonic and ranking descriptive analysis scores of Cheddar cheeses derived from TMR, perennial ryegrass (GRS), and perennial ryegrass and white clover (CLV) feeding systems after $180 \mathrm{~d}$ (A) and $270 \mathrm{~d}$ (B) of ripening. *Denotes attributes significantly different according to partial least squares regression statistical analysis. Color version available online. 
shows GRS (at 180 d) clustering with phenylalanine and leucine, which are associated with bitter sensory characters, whereas CLV and TMR were clustered with threonine, glycine, serine, and lysine, which have sweet sensory characters (Kilcawley, 2017). Negative scores for color of TMR cheese could be a result of the sensory panel having predominantly Irish participants, who would be more accustomed to the yellower GRS and CLV dairy products. The significantly higher concentrations of 2,3-butanediol in TMR cheeses could contribute to fruity estery flavor scores.

Sensory scores for each of the Cheddar cheeses between 180 and $270 \mathrm{~d}$ of ripening could be related to previously discussed attributes of the cheeses. Pearson correlation matrix analysis revealed that the sensory scores for liking of texture were negatively correlated with the level of primary proteolysis $(P=0.019, \mathrm{r}=$ $-0.545)$. Color scores from sensory panelists were negatively correlated with cheese $\mathrm{L}^{*}$ values $(P=0.002 ; \mathrm{r}=$ $-0.681)$ and positively correlated with cheese $b^{*}$ values $(P<0.001 ; \mathrm{r}=0.904)$. Sensory scores for firmness in mouth during ripening were negatively correlated with the level of proteolysis $(P=0.012 ; \mathrm{r}=-0.578)$, whereas crumbly texture scores were positively correlated with level of proteolysis $(P=0.025 ; \mathrm{r}=0.525)$. The levels of FAA were also negatively correlated with sensory scores for sweaty/sour aroma $(P=0.002 ; \mathrm{r}=-0.687)$, sweet taste $(P=0.002 ; \mathrm{r}=-0.667)$, sour taste $(P=$ $0.010 ; \mathrm{r}=-0.591)$, dairy sweet flavor $(P=0.027 ; \mathrm{r}=$ $-0.520)$, dairy fat flavor $(P<0.001 ; \mathrm{r}=-0.790)$, and fruity estery flavor $(P<0.001 ; \mathrm{r}=-0.759)$ scores. The FAA content of the cheeses was, however, positively correlated with salt taste scores for cheeses $(P<0.001$; $\mathrm{r}=0.748)$ from panelists after 180 and $270 \mathrm{~d}$ of ripening. Overall, these data indicate that feeding system has a significant effect on the organoleptic properties of Cheddar cheese and, in particular, that the significant differences in the $\beta$-carotene content of cheeses resulted in differences in color, such that pasture-derived cheeses scored higher for color intensity attribute. Levels of primary and secondary proteolysis were also correlated with alterations of several sensory attributes of the cheeses. Interestingly, toluene was significantly and positively correlated with the color attribute scores $(P=0.001 ; \mathrm{r}=0.724)$ and the cheese $\mathrm{b}^{*}$ values $(P=$ $0.001 ; \mathrm{r}=0.708)$ and was negatively correlated with cheese $L^{*}$ values $(P=0.020 ; \mathrm{r}=-0.559)$, which is in agreement with our previous study with butter from these feeding systems, where toluene was significantly correlated with pasture-derived products rather than those derived from TMR feeding system (O'Callaghan et al., 2016a). Given this result across several products, toluene may be a potential compound for verification of pasture-derived dairy products.

\section{CONCLUSIONS}

In this study, we demonstrated that pasture-derived feeding systems lead to production of Cheddar cheeses with a healthier fatty acid profile and yellower in color (because of increased $\beta$-carotene content) compared with a TMR feeding system. The fatty acid profile of Cheddar cheese was enhanced through pasture-based feeding systems, with significantly lower thrombogenicity index scores and a $>2$-fold increase in the concentration of CLA c9t11 isomer and VA. In contrast, TMRderived cheeses had significantly higher palmitic acid content. Pasture-derived Cheddar cheese was shown to have significantly higher n-3 fatty acid contents, whereas TMR cheese had significantly higher n-6 fatty acid content. Such alterations in the fatty acid profile of the cheeses resulted in pasture-derived cheese having reduced hardness scores at room temperature. Feeding system and ripening time had a significant effect on the volatile and sensory profile of the Cheddar cheese. Fatty acid profiling of cheese coupled with multivariate analysis showed clear separation of Cheddar cheese derived from pasture-based diets (perennial ryegrass or perennial ryegrass/white clover) from cheeses derived from a TMR system.

\section{ACKNOWLEDGMENTS}

This publication has emanated from research conducted with the financial support of Teagasc, Science Foundation Ireland (SFI) under Grant Number SFI/12/ RC/2273 and the Dairy Levy Fund administered by Dairy Research Ireland. Tom F. O'Callaghan is the recipient of a Teagasc Walsh Fellowship. The valuable input of Elaine Patterson and Hope Faulkner (Teagasc Moorepark Food Research Center) is gratefully acknowledged. The authors sincerely thank the technical and farm staff at Moorepark for their excellent care of the experimental cows and assistance during the experiment.

\section{REFERENCES}

Aprea, E., A. Romanzin, M. Corazzin, S. Favotto, E. Betta, F. Gasperi, and S. Bovolenta. 2016. Effects of grazing cow diet on volatile compounds as well as physicochemical and sensory characteristics of 12-month-ripened Montasio cheese. J. Dairy Sci. 99:6180-6190.

Barberg, A., M. Endres, J. Salfer, and J. Reneau. 2007. Performance and welfare of dairy cows in an alternative housing system in Minnesota. J. Dairy Sci. 90:1575-1583.

Belviso, S., M. Giordano, P. Dolci, and G. Zeppa. 2011. Degradation and biosynthesis of terpenoids by lactic acid bacteria isolated from cheese: First evidence. Dairy Sci. Technol. 91:227-236.

British Standards Institution. 1976. Chemical analysis of cheese. Part 5: Determination of $\mathrm{pH}$ value. British Standard 770. British Standards Institution, London, UK.

Coakley, M., E. Barrett, J. Murphy, R. Ross, R. Devery, and C. Stanton. 2007. Cheese manufacture with milk with elevated conjugated 
linoleic acid levels caused by dietary manipulation. J. Dairy Sci. 90:2919-2927.

Collins, Y. F., P. L. McSweeney, and M. G. Wilkinson. 2003. Lipolysis and free fatty acid catabolism in cheese: a review of current knowledge. Int. Dairy J. 13:841-866.

Coppa, M., A. Ferlay, F. Monsallier, I. Verdier-Metz, P. Pradel, R. Didienne, A. Farruggia, M. Montel, and B. Martin. 2011. Milk fatty acid composition and cheese texture and appearance from cows fed hay or different grazing systems on upland pastures. J. Dairy Sci. 94:1132-1145.

Coulon, J.-B., A. Delacroix-Buchet, B. Martin, and A. Pirisi. 2004 Relationships between ruminant management and sensory characteristics of cheeses: a review. Lait 84:221-241.

Couvreur, S., C. Hurtaud, C. Lopez, L. Delaby, and J.-L. Peyraud. 2006. The linear relationship between the proportion of fresh grass in the cow diet, milk fatty acid composition, and butter properties. J. Dairy Sci. 89:1956-1969.

Curioni, P. M. G., and J. O. Bosset. 2002. Key odorants in various cheese types as determined by gas chromatography-olfactometry. Int. Dairy J. 12:959-984.

Dairou, V., and J. M. Sieffermann. 2002. A comparison of 14 jams characterized by conventional profile and a quick original method, the flash profile. J. Food Sci. 67:826-834.

Daun, H. 2005. Produce color and appearance. Pages 191-219 in Produce Degradation: Pathways and Prevention. O. Lamikanra and S. H. Imam, ed. CRC Press, Boca Raton, FL.

De Wit, M., G. Osthoff, B. C. Viljoen, and A. Hugo. 2005. A comparative study of lipolysis and proteolysis in Cheddar cheese and yeast-inoculated Cheddar cheeses during ripening. Enzyme Microb. Technol. 37:606-616.

Ellis, K. A., G. Innocent, D. Grove-White, P. Cripps, W. G. McLean, C. V. Howard, and M. Mihm. 2006. Comparing the Fatty Acid Composition of Organic and Conventional Milk. J. Dairy Sci 89:1938-1950.

Fellendorf, S., M. G. O'Sullivan, and J. P. Kerry. 2015. Impact of varying salt and fat levels on the physicochemical properties and sensory quality of white pudding. Meat Sci. 103:75-82.

Fellendorf, S., M. G. O'Sullivan, and J. P. Kerry. 2016. Impact of ingredient replacers on the physicochemical properties and sensory quality of reduced salt and fat black puddings. Meat Sci. 113:17-25.

Fenelon, M., P. O'Connor, and T. Guinee. 2000a. The effect of fat content on the microbiology and proteolysis in Cheddar cheese during ripening. J. Dairy Sci. 83:2173-2183.

Fenelon, M. A., and T. P. Guinee. 2000. Primary proteolysis and textural changes during ripening in Cheddar cheeses manufactured to different fat contents. Int. Dairy J. 10:151-158.

Fenelon, M. A., T. P. Guinee, C. Delahunty, J. Murray, and F. Crowe. 2000b. Composition and sensory attributes of retail cheddar cheese with different fat contents. J. Food Compos. Anal. 13:13-26.

Fox, P. 1989. Proteolysis during cheese manufacture and ripening. J. Dairy Sci. 72:1379-1400.

Fox, P., and P. McSweeney. 1996. Proteolysis in cheese during ripening. Food Rev. Int. 12:457-509.

Gan, H. H., B. Yan, R. S. T. Linforth, and I. D. Fisk. 2016. Development and validation of an APCI-MS/GC-MS approach for the classification and prediction of Cheddar cheese maturity. Food Chem. 190:442-447.

Guinee, T. P., M. A. Auty, and M. A. Fenelon. 2000. The effect of fat content on the rheology, microstructure and heat-induced functional characteristics of Cheddar cheese. Int. Dairy J. 10:277-288.

Gunasekaran, S., and M. M. Ak. 2002. Cheese rheology and texture. CRC press.

Hassan, F. A., M. A. M. A. El-Gawad, and A. Enab. 2013. Flavour compounds in cheese. Research on Precision Instrument and Machinery 2:15-29. (review).

Henneberry, S., M. G. O'Sullivan, K. N. Kilcawley, P. M. Kelly, M. G. Wilkinson, and T. P. Guinee. 2016. Sensory quality of unheated and heated Mozzarella-style cheeses with different fat, salt and calcium levels. Int. J. Dairy Technol. 69:38-50.
Hickey, D. K., K. N. Kilcawley, T. P. Beresford, E. M. Sheehan, and M. G. Wilkinson. 2007. Starter strain related effects on the biochemical and sensory properties of Cheddar cheese. J. Dairy Res. $74: 9-17$.

Hickey, D. K., K. N. Kilcawley, T. P. Beresford, and M. G. Wilkinson. 2006. Starter bacteria are the prime agents of lipolysis in Cheddar cheese. J. Agric. Food Chem. 54:8229-8235.

Hou, J., J. A. Hannon, P. L. McSweeney, T. P. Beresford, and T. P. Guinee. 2012. Effect of curd washing on composition, lactose metabolism, $\mathrm{pH}$, and the growth of non-starter lactic acid bacteria in full-fat Cheddar cheese. Int. Dairy J. 25:21-28.

Hurtaud, C., J. L. Peyraud, G. Michel, D. Berthelot, and L. Delaby. 2009. Winter feeding systems and dairy cow breed have an impact on milk composition and flavour of two Protected Designation of Origin French cheeses. Animal 3:1327-1338.

IDF (International Dairy Federation). 1981. Cheese and processed cheese products - Determination of chloride content (potentiometer titration method). Standard 88A. International Dairy Federation, Brussels, Belgium.

IDF (International Dairy Federation). 1982. Cheese and processed cheese-Determination of the total solids content. Standard 4A. International Dairy Federation, Brussels Belgium.

IDF (International Dairy Federation). 1993. Milk determination of nitrogen content. Standard 20B. International Dairy Federation, Brussels, Belgium.

IDF (International Dairy Federation). 1996. Milk. Determination of fat content (Röse Gottlieb gravimetric method). IDF, Brussels, Belgium

ISO. 1988. Sensory analysis. General guidance for the design of test rooms. International Organization for Standardization (ISO), Geneva, Switzerland.

Juric, M., G. Bertelsen, G. Mortensen, and M. A. Petersen. 2003. Light-induced colour and aroma changes in sliced, modified atmosphere packaged semi-hard cheeses. Int. Dairy J. 13:239-249.

Karoui, R., and J. De Baerdemaeker. 2007. A review of the analytical methods coupled with chemometric tools for the determination of the quality and identity of dairy products. Food Chem. 102:621-640.

Khalid, N. M., and E. H. Marth. 1990. Lactobacilli-Their enzymes and role in ripening and spoilage of cheese: A review. J. Dairy Sci. 73:2669-2684.

Kilcawley, K. N. 2017. Cheese Flavour. Pages 443-474 in Fundamentals of Cheese Science. Springer US, Boston, MA.

Lucas, A., E. Rock, J.-F. Chamba, I. Verdier-Metz, P. Brachet, and J.-B. Coulon. 2006. Respective effects of milk composition and the cheese-making process on cheese compositional variability in components of nutritional interest. Lait 86:21-41.

Martin, B., I. Verdier-Metz, S. Buchin, C. Hurtaud, and J.-B. Coulon. 2005. How do the nature of forages and pasture diversity influence the sensory quality of dairy livestock products? Anim. Sci. $81: 205-212$.

McSweeney, P. L., and M. J. Sousa. 2000. Biochemical pathways for the production of flavour compounds in cheeses during ripening: A review. Lait 80:293-324.

Molendi-Coste, O., V. Legry, and I. A. Leclercq. 2011. Why and how meet n-3 PUFA dietary recommendations? Gastroenterol. Res. Pract. 2011:364040.

Noziere, P., B. Graulet, A. Lucas, B. Martin, P. Grolier, and M. Doreau. 2006. Carotenoids for ruminants: From forages to dairy products. Anim. Feed Sci. Technol. 131:418-450.

O'Brien, B., P. Dillon, J. J. Murphy, R. K. Mehra, T. P. Guinee, J. F. Connolly, A. Kelly, and P. Joyce. 1999. Effects of stocking density and concentrate supplementation of grazing dairy cows on milk production, composition and processing characteristics. J. Dairy Res. 66:165-176.

O'Callaghan, T. F., H. Faulkner, S. McAuliffe, M. G. O'Sullivan, D. Hennessy, P. Dillon, K. N. Kilcawley, C. Stanton, and R. P. Ross. 2016a. Quality characteristics, chemical composition, and sensory properties of butter from cows on pasture versus indoor feeding systems. J. Dairy Sci. 99:9441-9460. 
O'Callaghan, T. F., D. Hennessy, S. McAuliffe, K. N. Kilcawley, M. O'Donovan, P. Dillon, R. P. Ross, and C. Stanton. 2016b. Effect of pasture versus indoor feeding systems on raw milk composition and quality over an entire lactation. J. Dairy Sci. 99:9424-9440.

O'Donovan, M., E. Lewis, and P. O'Kiely. 2011. Requirements of future grass-based ruminant production systems in Ireland. Ir. J. Agric. Food Res. 50:1-21.

O'Mahony, J. A., J. Lucey, and P. McSweeney. 2005. Chymosin-mediated proteolysis, calcium solubilization, and texture development during the ripening of Cheddar cheese. J. Dairy Sci. 88:3101-3114.

Palmquist, D. L., A. Denise Beaulieu, and D. M. Barbano. 1993. Feed and animal factors influencing milk fat composition. J. Dairy Sci. $76: 1753-1771$

Richter, V. B., T. C. A. de Almeida, S. H. Prudencio, and M. de Toledo Benassi. 2010. Proposing a ranking descriptive sensory method. Food Qual. Prefer. 21:611-620.

Romanzin, A., M. Corazzin, E. Piasentier, and S. Bovolenta. 2013. Effect of rearing system (mountain pasture vs. indoor) of Simmental cows on milk composition and Montasio cheese characteristics. J. Dairy Res. 80:390-399.

Shalloo, L., P. Dillon, J. O'Loughlin, M. Rath, and M. Wallace. 2004. Comparison of a pasture-based system of milk production on a high rainfall, heavy-clay soil with that on a lower rainfall, freedraining soil. Grass Forage Sci. 59:157-168.

Sheehan, J. 2013. Milk quality and cheese diversification. Ir. J. Agric. Food Res. 52:243-253.

Singh, T. K., M. A. Drake, and K. R. Cadwallader. 2003. Flavor of Cheddar cheese: A chemical and sensory perspective. Compr. Rev. Food Sci. Food Saf. 2:166-189.

Siurana, A., and S. Calsamiglia. 2016. A metaanalysis of feeding strategies to increase the content of conjugated linoleic acid (CLA) in dairy cattle milk and the impact on daily human consumption. Anim. Feed Sci. Technol. 217:13-26.
Sousa, M., Y. Ardö, and P. McSweeney. 2001. Advances in the study of proteolysis during cheese ripening. Int. Dairy J. 11:327-345.

Stone, H., R. N. Bleibaum, and H. A. Thomas. 2012a. Chapter 7 - Affective Testing. Pages 291-325 in Sensory Evaluation Practices. 4th ed. H. Stone, R. N. Bleibaum, and H. A. Thomas, ed. Academic Press, San Diego, CA.

Stone, H., R. N. Bleibaum, and H. A. Thomas. 2012b. Test strategy and design of experiments. Pages 117-157 in Sensory Evaluation Practices. Vol. 4th. H. A. T. H. Stone Bleibaum R.N., ed. Elsevier Academic Press, Philadelphia, PA.

Stone, H., and J. L. Sidel. 2004. 7 - Affective Testing. Pages 247-277 in Sensory Evaluation Practices. 3rd ed. H. Stone and J. L. Sidel, ed. Academic Press, San Diego, CA.

Ulbricht, T., and D. Southgate. 1991. Coronary heart disease: Seven dietary factors. Lancet 338:985-992.

van Arendonk, J. A., and A.-E. Liinamo. 2003. Dairy cattle production in Europe. Theriogenology 59:563-569.

van Dorland, H. A., M. Kreuzer, H. Leuenberger, and H.-R. Wettstein. 2008. Comparative potential of white and red clover to modify the milk fatty acid profile of cows fed ryegrass-based diets from zerograzing and silage systems. J. Sci. Food Agric. 88:77-85.

Verkerk, G. 2003. Pasture-based dairying: Challenges and rewards for New Zealand producers. Theriogenology 59:553-561.

White, S. L., J. A. Bertrand, M. R. Wade, S. P. Washburn, J. T. Green, and T. C. Jenkins. 2001. Comparison of fatty acid content of milk from Jersey and Holstein cows consuming pasture or a total mixed ration. J. Dairy Sci. 84:2295-2301.

Yang, B., H. Chen, C. Stanton, R. P. Ross, H. Zhang, Y. Q. Chen, and W. Chen. 2015. Review of the roles of conjugated linoleic acid in health and disease. J. Funct. Foods 15:314-325. 